\title{
The Sinorhizobium fredii HH103 Genome: A Comparative Analysis With $S$. fredii Strains Differing in Their Symbiotic Behavior With Soybean
}

\author{
José-María Vinardell,, ${ }^{1}$ Sebastián Acosta-Jurado, ${ }^{1}$ Susanne Zehner, ${ }^{2}$ Michael Göttfert, ${ }^{2}$ Anke Becker, ${ }^{3}$ \\ Irene Baena, ${ }^{4}$ Jochem Blom, ${ }^{5}$ Juan Carlos Crespo-Rivas, ${ }^{1}$ Alexander Goesmann, ${ }^{5}$ Sebastian Jaenicke, ${ }^{5}$ \\ Elizaveta Krol, ${ }^{3}$ Matthew McIntosh, ${ }^{3}$ Isabel Margaret, ${ }^{1}$ Francisco Pérez-Montaño, ${ }^{1}$ \\ Susanne Schneiker-Bekel, ${ }^{5}$ Javier Serranía, ${ }^{3}$ Rafael Szczepanowski, ${ }^{5}$ Ana-María Buendía, ${ }^{1}$ \\ Javier Lloret, ${ }^{4}$ Ildefonso Bonilla, ${ }^{4}$ Alfred Pühler, ${ }^{5}$ José-Enrique Ruiz-Sainz, ${ }^{1}$ and Stefan Weidner ${ }^{5}$
}

${ }^{1}$ Departamento de Microbiología, Facultad de Biología, Universidad de Sevilla. Avda. Reina Mercedes 6, C.P. 41012 Sevilla, Spain; ${ }^{2}$ Technische Universität Dresden, Institut für Genetik, Helmholtzstrasse 10, 01062 Dresden, Germany; ${ }^{3}$ LOEWE Center for Synthetic Microbiology (SYNMIKRO) and Faculty of Biology, Philipps-Universität Marburg, Hans-Meerwein-Str. 6, 35043 Marburg, Germany; ${ }^{4}$ Departamento de Biología, Facultad de Ciencias, Universidad Autónoma de Madrid, Darwin 2, 28049Madrid, Spain; ${ }^{5}$ Centrum für Biotechnologie (CeBiTec), Universität Bielefeld, Universitaetsstr. 27, 33615 Bielefeld, Germany

Submitted 18 December 2015. Accepted 30 January 2015.

\begin{abstract}
Sinorhizobium fredii $\mathrm{HH103}$ is a fast-growing rhizobial strain infecting a broad range of legumes including both American and Asiatic soybeans. In this work, we present the sequencing and annotation of the $\mathrm{HH103}$ genome $(7.25 \mathrm{Mb})$, consisting of one chromosome and six plasmids and representing the structurally most complex sinorhizobial genome sequenced so far. Comparative genomic analyses of $S$. fredii $\mathrm{HH} 103$ with strains USDA257 and NGR234 showed that the core genome of these three strains contains 4,212 genes $(61.7 \%$ of the $\mathrm{HH} 103$ genes). Synteny plot analysis revealed that the much larger chromosome of USDA257 $(6.48 \mathrm{Mb})$ is colinear to the $\mathrm{HH} 103$ (4.3 Mb) and NGR324 chromosomes (3.9 Mb). An additional region of the USDA257 chromosome of about $2 \mathrm{Mb}$ displays similarity to plasmid pSfHH103e. Remarkable differences exist between HH103 and NGR234 concerning nod genes, flavonoid effect on surface polysaccharide production, and quorumsensing systems. Furthermore a number of protein secretion systems have been found. Two genes coding for putative type III-secreted effectors not previously described in $\mathrm{S}$. fredii, nopI and gunA, have been located on the HH103 genome. These differences could be important to understand the different symbiotic behavior of $S$. fredii strains HH103, USDA257, and NGR234 with soybean.
\end{abstract}

Rhizobia are $\alpha$ - and $\beta$-proteobacteria that are able to establish nitrogen-fixing symbioses with legumes. The enormous ecological and agricultural importance of legumes explains the extensive studies on the rhizobial-legume symbiosis carried out

Nucleotide sequence data are available at the EMBL database under accession numbers HE616890 to HE616893, HE616899, CDSA010000001 to CDSA010000004, and LN735562.

Corresponding author: José M. Vinardell; Telephone: +34-954554330; Fax: +34-954557830; E-mail: jvinar@us.es

*The $e$-Xtra logo stands for "electronic extra" and indicates that four supplementary tables are published online.

(C) 2015 The American Phytopathological Society during the last 40 years. The development of next generation sequencing technologies stimulated genomic studies of both symbiotic partners. The first rhizobial genomes sequenced and assembled were those of Sinorhizobium meliloti 1021 (Galibert et al. 2001) and Bradyrhizobium japonicum USDA110 (Kaneko et al. 2002), two strains that can be considered model symbionts. Since then, the number of available rhizobial genome sequences has notably increased (National Center for Biotechnology Information [NCBI] Microbial Genomes Resources database), although most of them are draft sequences or have not been manually annotated.

Sinorhizobium fredii is a rhizobial species that has an extremely broad host range (more than 100 genera of legumes are nodulated) that includes plants forming determinate nodules, such as Glycine max, as well as plants developing indeterminate nodules, such as Glycyrrhiza uralensis (Pueppke and Broughton 1999). Thus, studies on the diverse symbiotic signals produced by $S$. fredii strains are both interesting and complicated, since the relevance of each of these signals for symbiosis may vary with the host plant. Among the different $S$. fredii strains known, the three most studied so far are NGR234 (until recently known as Rhizobium sp.), USDA257, and HH103. In fact, genomic information is available for all of them. The sequence of the NGR234 genome was reported in 2009 by Schmeisser and colleagues, a draft of the USDA257 genome sequence has been announced recently by Schuldes et al. (2012), and we have already published our first studies on the HH103 genome (Margaret et al. 2011; Weidner et al. 2012).

There are differences between these three $S$. fredii strains regarding their nodulation host range, which makes them particularly interesting for comparative analyses. S. fredii NGR234 possesses the largest host range known so far. In a study carried out with 452 legumes (Pueppke and Broughton 1999), strain USDA257 nodulated an exact subset (79 genera) of the NGR234 hosts (112 genera). The HH103 host range has not been studied in such a detail, but it seems to be closer to that of USDA257 (Margaret et al. 2011). However, a few significant differences between these two strains exist. HH103 is able to induce $\mathrm{Fix}^{+}$nodules on Neonotonia wightii and Erythrina variegata (de Lyra et al. 2006), plants that are not nodulated by 
USDA257. An intriguing difference between these three strains lies in their symbiotic behavior with soybean, one of the most important crops worldwide; NGR234 does not induce the formation of Fix ${ }^{+}$nodules on soybean (Pueppke and Broughton 1999), USDA257 only does it on both wild and noncommercial varieties of soybeans (Heron and Pueppke 1984), and HH103 nodulates effectively both Asiatic and the commercial American soybeans (Dowdle and Bohlool 1985).

Here, we provide the first manually annotated genome sequence of a fast-growing rhizobial strain able to nodulate soybean. We describe the main characteristics of the $S$. fredii HH103 genome and present comparative analyses with the genomes of $S$. fredii strains NGR234 and USDA257.

\section{RESULTS AND DISCUSSION}

\section{Structure of the $S$. fredii $\mathbf{H H 1 0 3}$ genome.}

The genome sequence of $S$. fredii $\mathrm{HH} 103$ has been established by a combination of whole-genome shotgun and long paired-end sequencing. Finishing was performed by fosmid end-sequencing, polymerase chain reaction (PCR) product sequencing and primer walking. Details have already been provided (Weidner et al. 2012). In this previous work, we reported that the $S$. fredii HH103 genome was composed of six different replicons, i.e., the chromosome and five plasmids named pSfHH103a to pSfHH103e. In the meantime, sequencing reactions were carried out to close the few remaining gaps in plasmid pSfHH103d. As a result, the plasmid is now assembled into three contigs $(302,226,276,571$, and $10,000 \mathrm{bp})$ and a probable contig order was determined on the basis of PCR results and paired-end sequence information. Furthermore, the additional sequencing revealed the existence of a sixth plasmid that we named pSfHH103a2. This plasmid, with a size of 25,081 bp, was not detected by plasmid gel electrophoresis, since it comigrates with plasmid pSfHH103a1 (formerly called pSfHH103a, 24,036 bp).

The $S$. fredii $\mathrm{HH} 103$ genome is the most structurally complex genome sequenced among sinorhizobia (NCBI $S$. fredii database). Plasmids pSfHH103c, pSfHH103b, pSfHH103a1, and pSfHH103a2 are the smallest plasmids sequenced so far in Sinorhizobium spp. Other $S$. fredii strains such as USDA257 or NGR234 only contain one or two plasmids, respectively. Genome plots of all $S$. fredii HH103 replicons are shown in Figures 1 and 2 and their main characteristics are summarized in Table 1 . The total genome size was estimated to be $7.25 \mathrm{Mb}$, which is slightly larger than that of the other sequenced $S$. fredii strains, USDA257 (7.03 Mb; Schuldes et al. 2012) and NGR234 (6.89 Mb; Schmeisser et al. 2009). The global GC content was found to be $62.1 \%$ and is in the same range as the GC contents of the genomes of USDA257 (62.0\%) and NGR234 (62.2\%). The GC content of the S. fredii HH103 chromosome and the largest plasmid pSfHH103e (62.6 and $62.4 \%$, respectively) is, on average, $3.3 \%$ higher than the GC content of the other five plasmids.

Initially, an automatic gene prediction and annotation was performed (Weidner et al. 2012) using the GenDB system (Meyer et al. 2003). The automated annotation of each replicon including the newly identified plasmid pSfHH103a2 was now inspected and annotated manually. In total, 6,960 open reading frames (ORF) have been annotated in the genome of $S$. fredii $\mathrm{HH} 103$ (Table 1). In addition to 4,014 ORF, the chromosome contains three rRNA operons, and 53 tRNA genes, including five tRNAMet (CAT anticodon) genes. Plasmid pSfHH103d harbors an additional copy of the tRNA-Met (CAT anticodon), as it has been previously described for its counterparts in S. meliloti 1021 and S. fredii NGR234 (Barnett et al. 2001; Schmeisser et al. 2009).
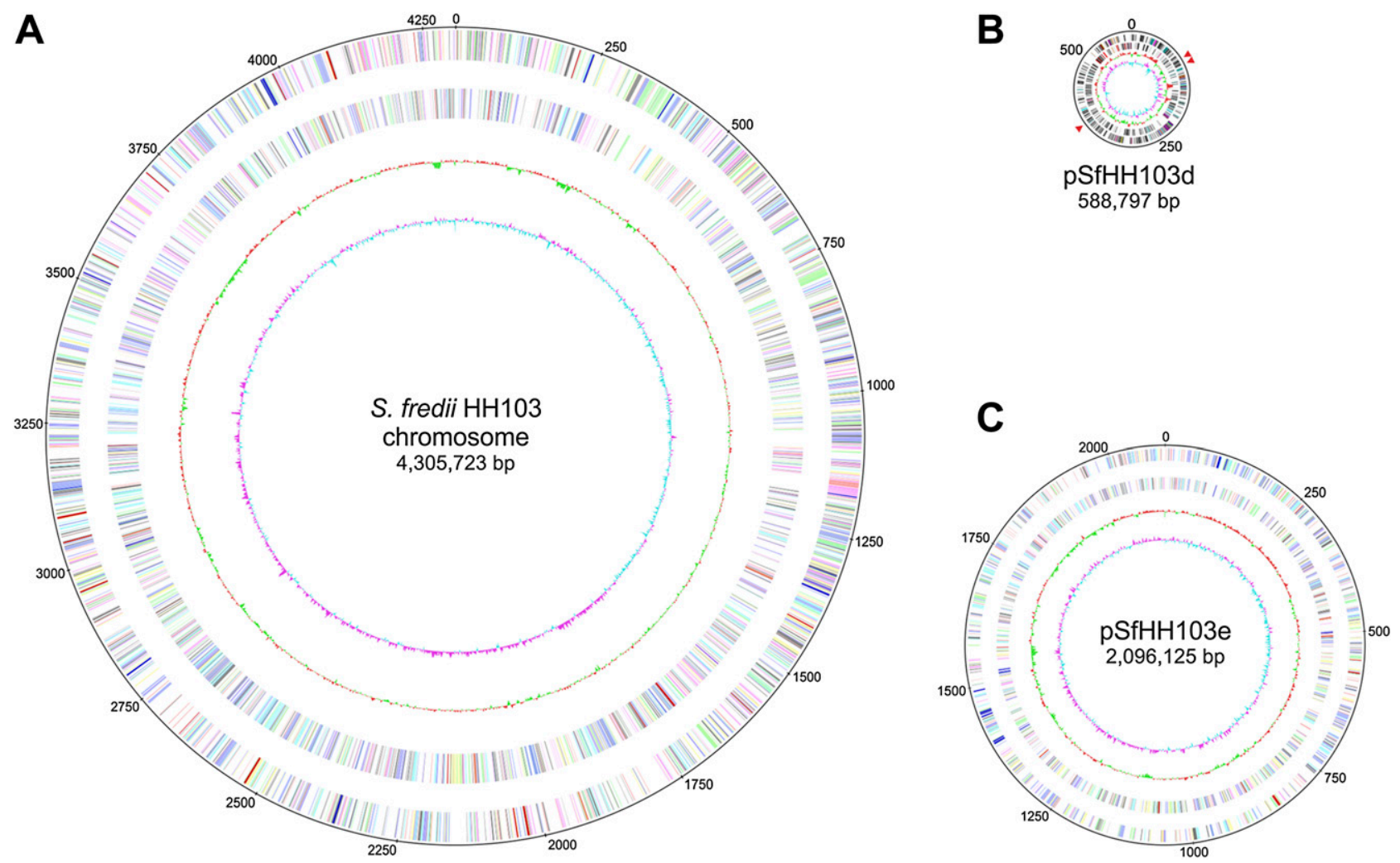

Fig. 1. Circular plots of A, the Sinorhizobium fredii HH103 chromosome and $\mathbf{B}$ and $\mathbf{C}$, the two largest plasmids pSfHH103d (B) and pSfHH103e (C). The maps display from the outer to the inner concentric circle. Circle 1, position in $\mathrm{kb} ; d n a A$ is the first gene of the chromosome and repA is the first gene of the two plasmids. Circles 2 and 3, predicted protein coding sequences on the forward and the reverse strand, respectively, and colored according to the assigned cluster of orthologous group classes. Circle 4, GC content showing deviations from the average. Circle 5, GC skew. Red triangles in B indicate the position of remaining sequence gaps. All three replicons are drawn in the same scale. 
S. fredii $\mathrm{HH} 103$ clusters of orthologous groups are distributed among the seven replicons constituting the HH103 genome (Supplementary Table S1). Genes related to surface polysaccharide production are mainly located on the chromosome and plasmid pSfHH103e, whereas nodulation and nitrogen-fixation proteins are encoded by plasmid pSfHH103d. A high number of secretion systems are encoded by the chromosome and plasmids pSfHH103c, pSfHH103d, and pSfHH103e. In addition to numerous hypothetical proteins of unknown function, plasmids pSfHH103b, pSfHH103a1, and pSfHH103a2 mainly encode proteins related to plasmid maintenance and transposable elements. The low GC content of plasmids pSfHH103c, pSfHH103b, pSfHH103a1, and pSfHH103a2 suggests that they could have been acquired by horizontal transfer.

Genomes constituted by several replicons are prevalent among plant symbionts (diCenzo et al. 2014). In some rhizobia, in addition to the chromosome (usually the largest replicon containing most of the core genes), plasmids-which were subsequently called chromids - carrying some core genes have also been found (Harrison et al. 2010). This is the case for plasmid pSymB of S. meliloti 1021, which carries the essential genes tRNA ${ }^{\text {arg }}$ and engA (diCenzo et al. 2013). In $S$. fredii HH103, however, these genes are located on the chromosome. As in S. meliloti 1021 and $S$. fredii NGR234, the minCDE genes are located on the largest $\mathrm{HH} 103$ plasmid (pSfHH103e). These genes, which in Escherichia coli are required for cell division, are not essential for cell growth in S. meliloti (Cheng et al. 2007). Thus, at this moment, further studies are required in order to know whether plasmid pSfHH103e, which is larger (2.10 Mbp) than S. meliloti pSymB (1.68 Mbp), carries HH103 core genes. In the case of pSfHH103d, we have failed in several attempts to obtain a $\mathrm{HH} 103$ derivative lacking this plasmid by using chemical agents such as sodium dodecyl sulfate (SDS), ethidium bromide, or acridine orange (our own unpublished
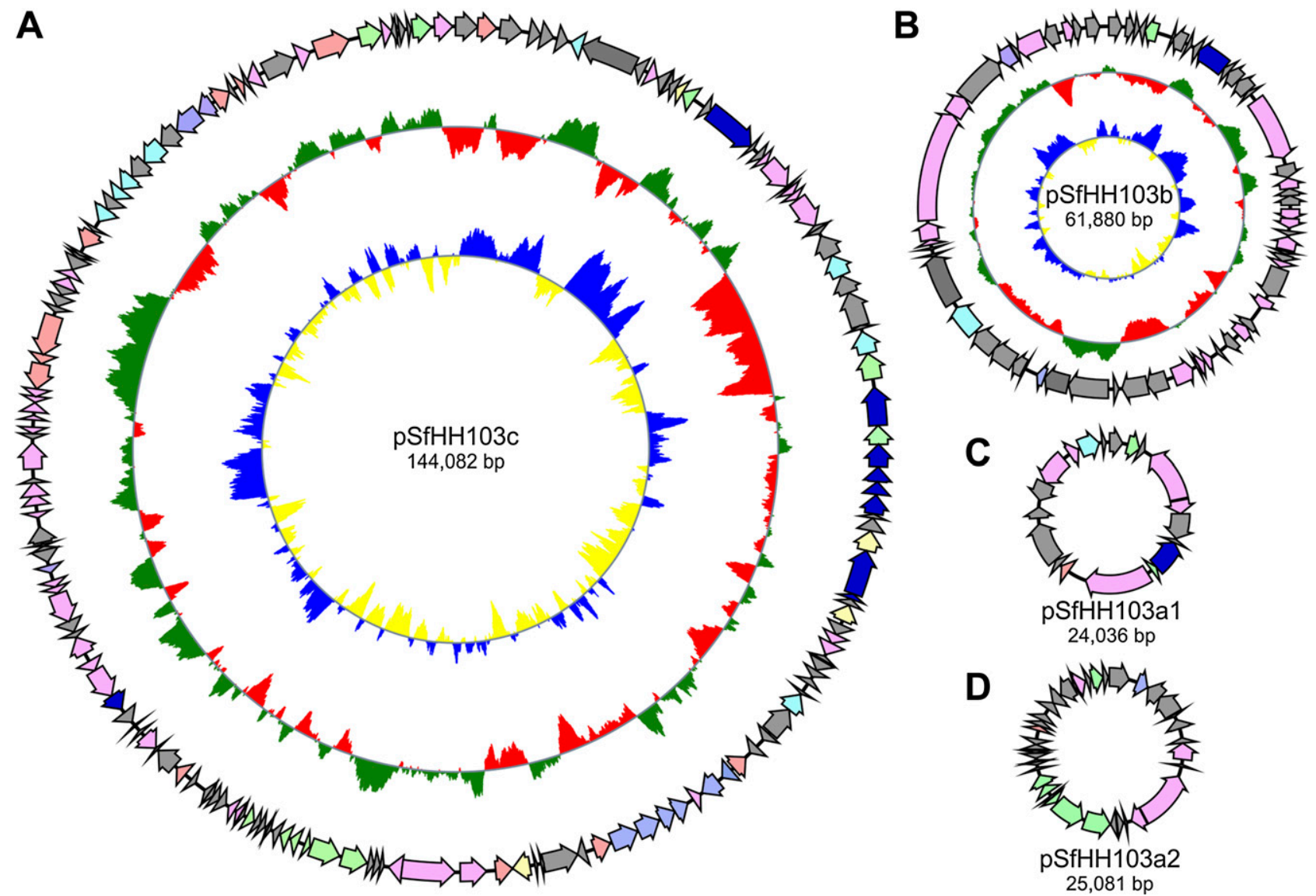

Fig. 2. Circular plots of the Sinorhizobium fredii HH103 smaller plasmids A, pSfHH103c, B, pSfHH103b, C, pSfHH103a1, and D, pSfHH103a2. The first gene at the top of each plot is repA. The maps display from the outer to the inner concentric circle. Circle 1, predicted protein coding sequences as arrows, colored according to the assigned cluster of orthologous group classes. Circle 2, GC content showing deviations from the average. Circle 3, GC skew. For the two smallest plasmids (C and D) the latter two circles are not shown. All four replicons are drawn in the same scale.

Table 1. General features of the Sinorhizobium fredii HH103 genome

\begin{tabular}{|c|c|c|c|c|c|c|c|}
\hline Replicon & Chromosome & pSfHH103e & pSfHH103d & pSfHH103c & pSfHH103b & pSfHH103a1 & pSfHH103a2 \\
\hline Length (bp) & $4,305,723$ & $2,096,125$ & approximately $588,797^{\mathrm{a}}$ & 144,082 & 61,880 & 24,036 & 25,081 \\
\hline GC content $(\%)$ & 62.61 & 62.38 & 59.59 & 58.68 & 58.47 & 58.21 & 58.02 \\
\hline Genome coding $(\%)$ & 86.61 & 87.81 & 85.08 & 87.45 & 85.38 & 84.52 & 82.16 \\
\hline Coding sequence (CDS) & 4,014 & 1,991 & 667 & 169 & 62 & 19 & 38 \\
\hline Maximum CDS length (bp) & 8,628 & 5,451 & 8,457 & 3,078 & 5,985 & 3,486 & 2,898 \\
\hline Mean CDS length (bp) & 929.05 & 924.42 & 751.06 & 745.58 & 852.19 & $1,069.26$ & 542.29 \\
\hline t-RNA genes & 53 & 0 & 1 & 0 & 0 & 0 & 0 \\
\hline$r r n$ operons & 3 & 0 & 0 & 0 & 0 & 0 & 0 \\
\hline
\end{tabular}

${ }^{a}$ Three concatenated contigs. 
results), which suggests that this plasmid could contain genes required for growth under the experimental conditions used.

In order to investigate whether HH103 plasmids pSfHH103a1, pSfHH103b, or pSfHH103c could carry essential genes, each of these plasmids was tagged individually with the $s a c B R$ genes of Bacillus subtilis (discussed below), which confers sucrose sensitivity to gram-negative bacteria, including $S$. fredii strains

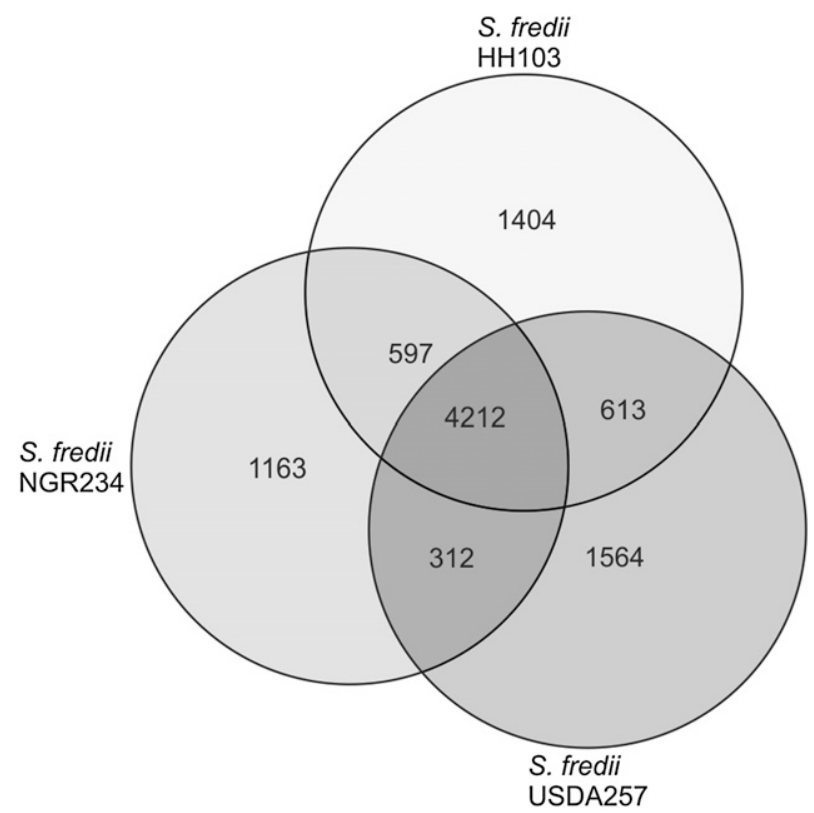

Fig. 3. Comparative analysis of the genomes of Sinorhizobium fredii HH103, NGR234, and USDA257. The differential gene content is visualized in a Venn diagram. Circles represent the three individual genomes overlapping with each other in all possible combinations. Numbers indicate the number of genes that are either individual for a certain genome or that are present in two or three genomes.
(Vinardell et al. 1997). Strains growing in the presence of $12.5 \%$ sucrose were tested for the presence of the corresponding plasmids. We obtained $\mathrm{HH} 103$ derivatives cured of plasmid pSfHH103c or plasmid pSfHH103a1. These derivatives were fully effective in symbiosis and nitrogen fixation with soybean, Vigna unguiculata, and Cajanus cajan (data not shown). Furthermore, they did not show detectable growth defects in tryptone yeast (TY) and yeast mannitol agar media. All our attempts to cure the strain of plasmid pSfHH103b were unsuccessful, which suggests that this plasmid could be relevant for bacterial growth under laboratory conditions or that the plasmid encodes a so-far-unknown toxinantitoxin system. In addition to transposable elements and genes required for plasmid maintenance, plasmid pSfHH103b encodes a number of hypothetical proteins whose functions remain to be elucidated.

Comparative analysis of the $S$. fredii $\mathrm{HH103}$ genome.

Analysis and interpretation of the $S$. fredii $\mathrm{HH} 103$ genome sequence by means of the comparative genomics tool EDGAR (Blom et al. 2009) have been performed with the two other completely sequenced $S$. fredii strains NGR234 and USDA257. The core genome of all three strains comprises 4,212 genes and represents $61.7 \%$ of all S. fredii $\mathrm{HH} 103$ genes (Fig. 3). With 2,902 genes $(68.9 \%)$, the majority is located on the chromosomes of the compared strains (data not shown). Pairwise comparisons of HH103 with strains NGR234 and USDA257 showed nearly identical numbers of orthologs $(4,809$ and 4,825 , respectively), whereby the distribution of these genes among the replicons differs. Synteny plots were carried out to analyze the colinearity of the HH103, NGR234, and USDA257 chromosomes. The much larger chromosome of USDA257 $(6.48 \mathrm{Mb})$ was found to be colinear to the HH103 and the NGR234 chromosome, but the synteny was interrupted by a region of about $2 \mathrm{Mb}$, which displayed similarity to pSfHH103e (Fig. 4). These findings were further analyzed by comparing the chromosome sequences of USDA257 and

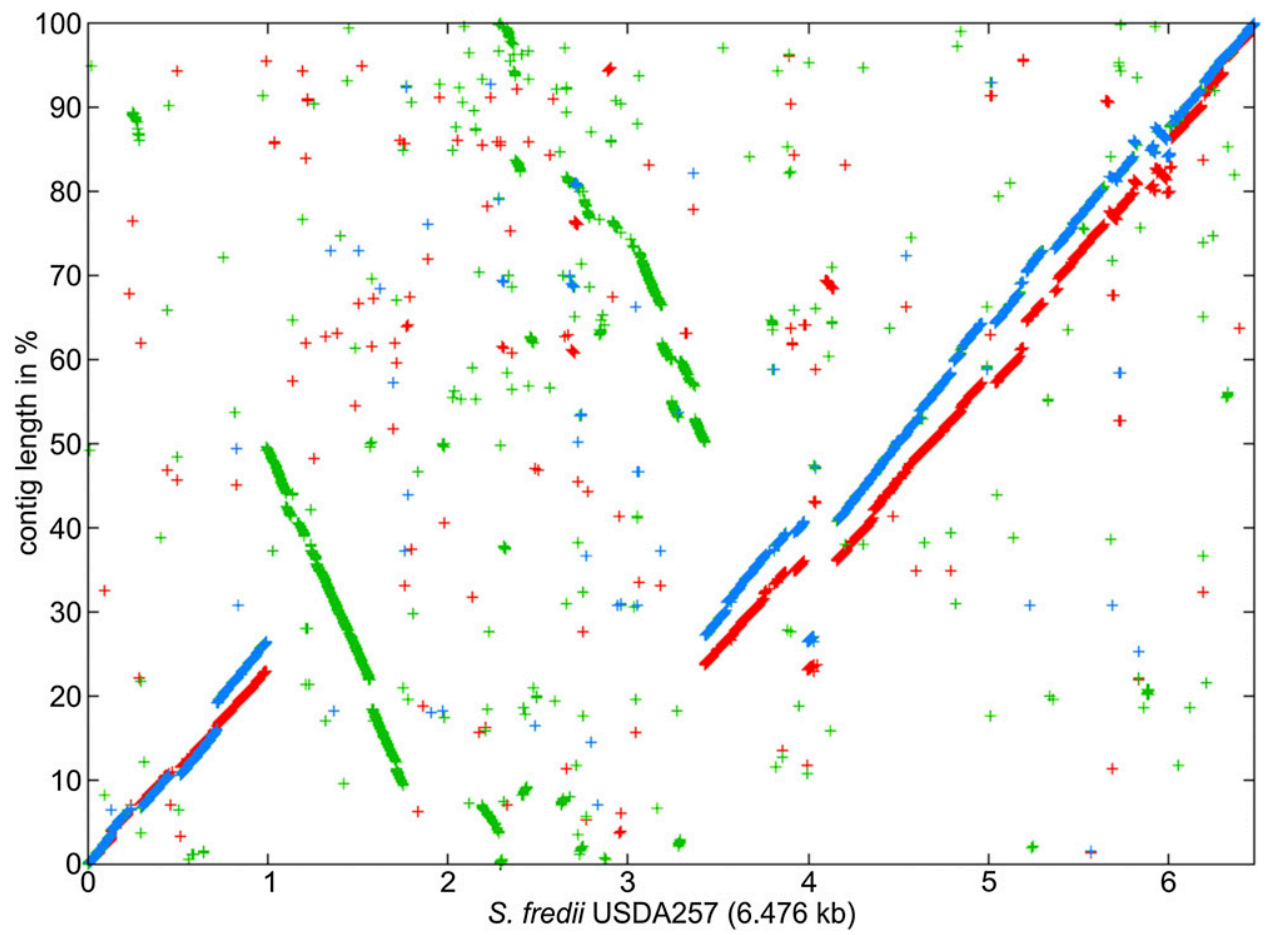

Fig. 4. Synteny plot of the chromosomes of Sinorhizobium fredii USDA257, NGR234, HH103, and plasmid pSfHH103e. Due to its greater length, the USDA257 chromosome serves as the reference and is displayed on the $x$ axis, whereas the other replicons are displayed on the $y$ axis on a relative scale. Every coding sequence of the reference is checked for a reciprocal best blast hit against the other replicons. The positions on the replicons of these hit coding sequences are shown by crosses, whereby blue represents hits to $S$. fredii NGR234, red to HH103, and green to pSfHH103e. 
HH103 using the Artemis Comparison Tool (Carver et al. 2005). The high colinearity of the HH103 and the muchlarger USDA257 chromosome could be confirmed. Again, it could be shown that a region of about $2 \mathrm{Mb}$ displays similarity to the pSfHH103e plasmid (Fig. 5). The results obtained clearly demonstrate that the different chromosome sizes of $S$. fredii USDA257 and HH103 can be explained by the existence of a large plasmid, which is integrated into the genome of USDA257 and which exists independently of the chromosome in the case of HH103.

\section{S. fredii HH103 genes involved in Nod factor biosynthesis.}

The set of lipo-chitooligosaccharides (LCO) produced by HH103 is less diverse than that of NGR234 and similar to that of USDA257 (Bec-Ferté et al. 1994; Gil-Serrano et al. 1997; Pueppke and Broughton 1999). HH103 and USDA257 LCO, in contrast to NGR234 Nod factors, are not decorated with acetyl, carbamoyl, $N$-methyl, and sulfate groups.

As in other sinorhizobia, HH103 genes involved in Nod factor production are located on the so-called symbiotic plasmid $(=\mathrm{pSym}$, pSfHH103d). The nodulation genes are organized in two clusters (Lamrabet et al. 1999; Madinabeitia et al. 2002), the operon nodABCIJnolO'noeI (psfHH103d_126 to psfHH103d_132) and the nolK-noeL-nodZ-noeK and noeJ genes (psfHH103d_379 to psfHH103d_383). These genes account for the different Nod factors produced by HH103: oligomers of three to five $\beta(1 \rightarrow 4)$-linked $\mathrm{N}$-acetyl-glucosamine (GlcNAc) residues bearing an amide-bound fatty acyl residue, saturated or unsaturated, on the nonreducing terminal GlcNAc residue and a fucose or metylfucose modification at the $\mathrm{C} 6$ position of the reducing GlcNAc residue (Gil-Serrano et al. 1997).

There are some important differences in the set of nodulation genes harbored by $\mathrm{HH} 103$ and its closely related strain NGR234, which is in agreement with the different sets of LCO produced by these strains. In fact, the only nod genes involved in the decoration of LCO in HH103 are nolK-noeL-nodZ-noeK and noeJ (required for fucosylation) and noeI (methylation of the fucosyl residue). Genes nolL and noeE, which account for the acetylation and sulfation, respectively, of NGR234 LCO, are missing in $\mathrm{HH} 103$.

Also missing are carbamoyl substitutions. In NGR234, there are two nod genes involved in carbamoylation of LCO, namely, nolO and nodU (Jabbouri et al. 1995, 1998). We previously demonstrated that the nolO gene of $\mathrm{HH} 103$ (called $n o l O^{\prime}$ ) is truncated due to a-1-bp frameshift mutation located between nucleotides 231 and 232 of the nolO' coding region (Madinabeitia et al. 2002). This deletion, conserved in other soybean-nodulating S. fredii strains, such as USDA192, USDA193, USDA257, and 042B strains, generates a premature stop codon. Sequencing of the $\mathrm{HH} 103$ genome revealed that the nod $U$ gene is also truncated and divided into two pseudogenes, called psfHH103d_453 and psfHH103d_454, and this is also the situation for USDA257. Thus, both genes involved in carbamoylation of NGR234 Nod factors, nolO and nod $U$, are truncated and presumably nonfunctional in S. fredii $\mathrm{HH} 103$ and USDA257. Interestingly, LCO of another soybean symbiont, Bradyrhizobium japonicum USDA110, are also noncarbamoylated (Sanjuan et al. 1992). In fact, the sets of LCO produced by $B$. japonicum USDA110 and $S$. fredii strains HH103 and USDA257 are relatively similar (D'Haeze and Holsters 2002; Margaret et al. 2011) and different from those produced by NGR234. Whether this difference in the set of Nod factors produced by USDA110, HH103, and USDA257 with respect to that produced by NGR234 could be related with the ability or inability to nodulate soybean requires further investigation.

In $S$. fredii NGR234, nodU is preceded by nodS and both genes are under the transcriptional control of nod box 12 (NB12). NodS is involved in $N$-methylation of Nod factors, which is required for nodulation of Leucaena spp. (Krishnan et al. 1992). The annotated nodS gene of HH103 (psfHH103d_452) encodes a putative polypeptide of 181 amino acids, which is 99\% identical to the 216-residue NodS protein of NGR234 in the last 140 amino acid residues. The nod box located upstream of psfHH103d_452-psfHH103d_454 is also different from that of NGR234 but identical to that found in $S$. fredii USDA257, which is nonfunctional (Krishnan et al. 1992).

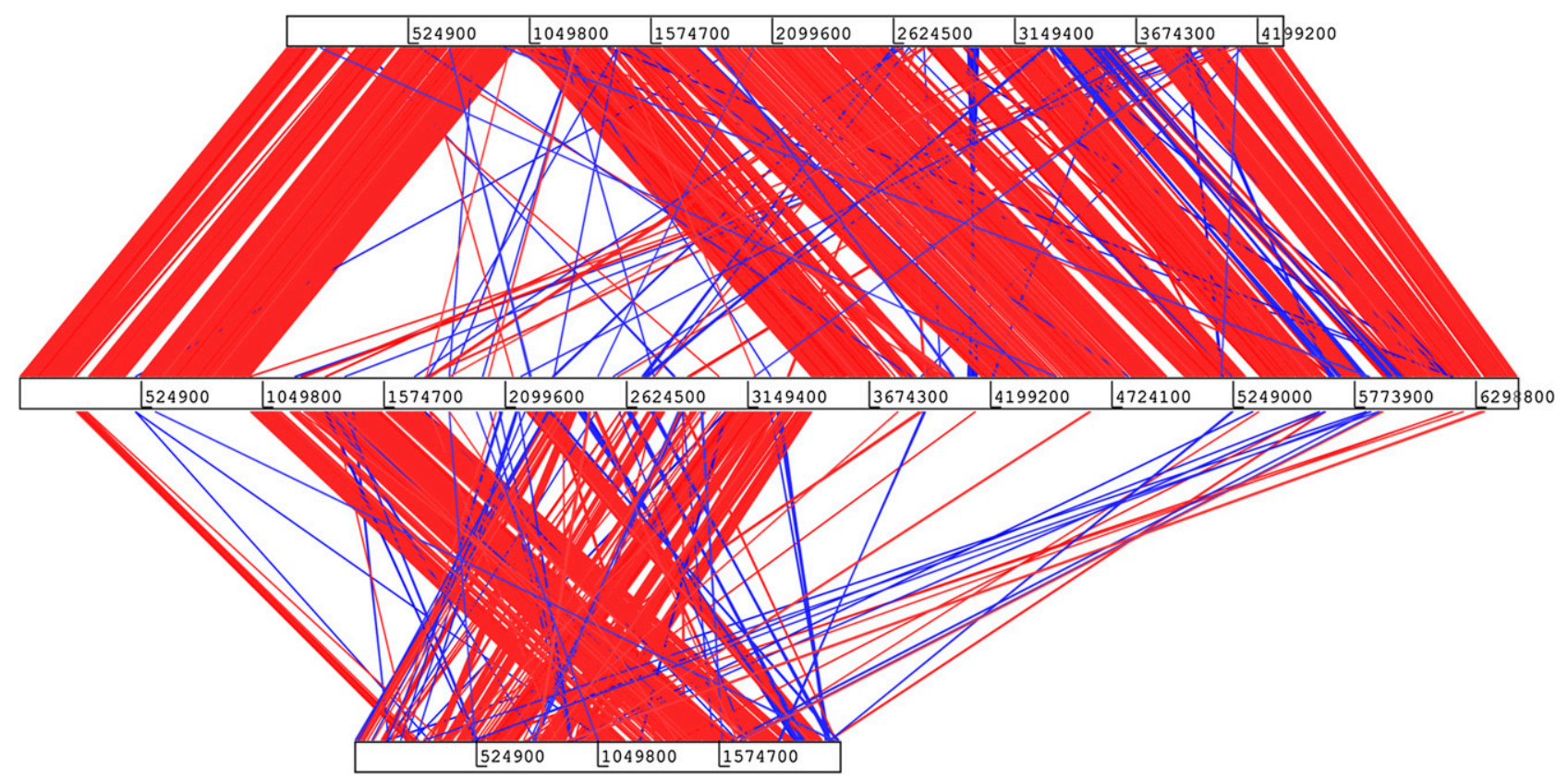

Fig. 5. Comparison of the chromosomes of Sinorhizobium fredii HH103 and USDA257 and plasmid pSfHH103e. The three replicons are displayed in linear form as boxes: Top, $S$. fredii $\mathrm{HH} 103$ chromosome; middle, $S$. fredii USDA257 chromosome; bottom, $S$. fredii pSfHH103e. Numbers indicate the position on the respective replicon in base pairs. Red blocks link similar DNA regions between two replicons, blue lines link similar DNA regions inverted to each other. The minimum length of similar regions shown was set to $600 \mathrm{bp}$. 
Most probably, either the nodS gene or the nod box is nonfunctional in $S$. fredii $\mathrm{HH} 103$. Altogether, two coherent observations are that $\mathrm{HH} 103 \mathrm{LCO}$ are not $N$-methylated (Gil-Serrano et al. 1997) and this strain fails to nodulate Leucaena leucocephala (our unpublished data).

In addition to the structural nod genes, several symbiotic regulatory genes are also harbored by plasmid pSfHH103d, including two copies of nodD, nodD1 (psfHH103d_386) and nodD2 (psfHH103d_320) (Machado et al. 1998; Vinardell et al. 2004a), syrM, and ttsI (López-Baena et al. 2008). The symbiotic regulator nolR (Vinardell et al. 2004b), as in S. meliloti and S. fredii NGR234, is located on the chromosome (SFHH103_02239).

\section{S. fredii strains contain a similar set of nod box-associated genes.}

In addition to known nodulation genes, a number of NGR234 pSymA genes have been shown to be under the transcriptional control of nod boxes (NB) (Perret et al. 1999). Most, but not all, of these genes as well as their NB are conserved in $S$. fredii HH103 (Table 2).

Flavonoids, NodD1, and NodD2 modulate expression of the NGR234 $y 4 w E F G$ locus, which is located downstream of NB15 and which is required for indole-3-acetic acid (IAA) synthesis (Theunis et al. 2004). However, mutations in the $y 4 w E F G$ locus apparently do not affect symbiosis. Although the functionality of NB15 in strain HH103 has not been analyzed, the two genes located downstream (psfHH103d_257 and psfHH103d_258) are likely to encode a histidinol-phosphate aminotransferase and a monooxygenase oxidoreductase. Our preliminary experiments indicate that the production of IAA by HH103 in minimal medium is increased about eightfold upon induction with genistein (data not shown), which suggests that these HH103 genes could be involved in genistein-mediated production of IAA. The putative symbiotic role of a number of $S$. fredii genes located downstream of nod boxes (Table 2) remains to be studied, e.g., genes that are likely to encode phytoene or squalene synthase (downstream of NB1) or a periplasmic solute-binding protein (downstream of NB17).

\section{Genes involved in polysaccharide production.}

Exopolysaccharides (EPS), lipopolysaccharides (LPS), capsular polysaccharides (KPS [K-antigen polysaccharides]), and cyclic glucans are the main rhizobial polysaccharides that are relevant for symbiosis (Downie 2010). We have previously described S. fredii HH103 genes (Supplementary Table S2) involved in the production of these polysaccharides: $n d v B$, which is required for production of cyclic glucans (Crespo-Rivas et al. 2009), the lpsBCDE genes, which are involved in LPS core biosynthesis (Margaret et al. 2013), the $r k p-1$ and $r k p-3$ regions, which participate in KPS production (Hidalgo et al. 2010; Margaret et al. 2012; Margaret-Oliver et al. 2012; Parada et al. 2006), and the exo cluster responsible for EPS production (Rodríguez-Navarro et al. 2014). As in other rhizobia, all these genes are located either on the largest megaplasmid (pSfHH103e) or on the chromosome.

In the HH103 genome sequence additional genes related to surface polysaccharide production were found, such as the chromosomal $r k p-2$ region, which, in $S$. meliloti $\mathrm{Rm} 41$, is necessary for KPS synthesis and which affects LPS production (Kereszt et al. 1998). This region comprises two genes, $l p s L$ and $r k p K$, whose encoded products (a UDP-glucuronate 4-epimerase and a UDP-glucose 6-dehydrogenase respectively) are 91 and $88 \%$ identical to the respective proteins of $\mathrm{Rm} 41$. The involvement of the HH103 rkp-2 region in surface polysaccharide production is currently being analyzed. On plasmid pSfHH103e, orthologs of the $S$. meliloti 1021 exsIEDCBA genes have been located next to the exoBZQFY2XUIKLAMONP genes. There are several other genes putatively involved in EPS production: exoFY1

Table 2. Comparison of nod boxes (NB) present in the symbiotic plasmids of Sinorhizobium fredii strains NGR234, HH103, and USDA257

\begin{tabular}{|c|c|c|c|}
\hline \multirow[b]{2}{*}{$\mathbf{N B}^{\mathbf{a}}$} & \multicolumn{2}{|c|}{ Genes located downstream } & \multirow[b]{2}{*}{ Identity $^{c}$} \\
\hline & NGR234 & HH103 $^{b}$ & \\
\hline 1 & $\begin{array}{l}\text { Hypothetical proteins, phytoene/squalene } \\
\text { synthases }\end{array}$ & $\begin{array}{l}\text { Similar to NGR234 } \\
\text { psfHH103d_370 to } 373\end{array}$ & $48 / 49(98 \%)$ \\
\hline 2 & nodZnoeLnolK & psfHH103d_381 to $379^{\mathrm{d}}$ & $47 / 49(96 \%)$ \\
\hline 3 & nodD1 (opposite sense) & psfHH103d_386 ${ }^{\mathrm{d}}$ & $49 / 49(100 \%)$ \\
\hline 4 & nolL & Not present $\mathrm{e}^{\mathrm{e}}$ & \\
\hline 5 & None & None & $\begin{array}{c}\text { 48/49 }(98 \%) \\
1 \text { gap }\end{array}$ \\
\hline 6 & fix $F$ & Not present ${ }^{\mathrm{e}}$ & \\
\hline 7 & noeE & Not present $\mathrm{e}^{\mathrm{e}}$ & \\
\hline 8 & nodABCIJnolOnoeI & psfHH103d_126 to 132 , nolO is truncated & $47 / 49(96 \%)$ \\
\hline 9 & Hypothetical protein, putative oxidoreductase & psfHH103d_118, $116^{\mathrm{d}}$ & $49 / 49(100 \%)$ \\
\hline 10 & $\begin{array}{l}\text { Gene encoding a protein showing } 58 \% \\
\text { identity to PsiB }\end{array}$ & psfHH103d_16 ${ }^{\mathrm{d}}$ & $48 / 49(98 \%)$ \\
\hline 11 & $\begin{array}{l}\text { NGR234_234 (precursor of } 26.2 \mathrm{kDa} \text { for conserved } \\
\text { putative periplasmic protein) }\end{array}$ & Not present ${ }^{\mathrm{e}}$ & \\
\hline 12 & nodSU & psfHH103d_452 to 454 , nodU is truncated & $43 / 45(96 \%)$ \\
\hline 13 & None & psfHH103d_448, hypothetical protein & $46 / 47(98 \%)$ \\
\hline 14 & Conserved hypothetical $11.0 \mathrm{kDa}$ protein, fix $A B C X$ & Similar to NGR234, psfHH103d_230 to 224 & $49 / 49(100 \%)$ \\
\hline 15 & Proteins involved in flavonoid-dependent IAA synthesis & psfHH103d_257, 258 ${ }^{\text {d }}$ & $47 / 49(96 \%)$ \\
\hline 16 & $\operatorname{virK}$ & None $\mathrm{f}^{\mathrm{f}}$ & $49 / 49(100 \%)$ \\
\hline 17 & $\begin{array}{l}\text { Conserved periplasmic solute-binding } \\
\text { protein of } \mathrm{ABC} \text {-transporter }\end{array}$ & psfHH103d_208 ${ }^{\mathrm{d}}$ & $49 / 49(100 \%)$ \\
\hline 18 & $t t s I$ & psfHH103d_323 ${ }^{\mathrm{d}}$ & $48 / 49(98 \%)$ \\
\hline 19 & syrM2 & psfHH103d_367 & $48 / 49(98 \%)$ \\
\hline
\end{tabular}

a As defined by Perret et al. 1999.

${ }^{\mathrm{b}}$ Genes located downstream of nod boxes in strain USDA257 are the same as in HH103, with the only exception of NB13, for which no gene was found in USDA257.

c NGR234/HH103. All the USDA257 nod boxes analyzed are 100\% identical to those of HH103.

$\mathrm{d}$ The genes are the same as in NGR234.

e Neither this nod box nor the affiliated gene of NGR234 are present in HH103.

${ }^{\mathrm{f}}$ virK is present but is not under the control of a nod box. 
and exsFGH (located on pSfHH103e), as well as exoR, exoN, exoS, and exoD (located on the chromosome). In addition, the predicted product of SFHH103_00951 belongs to the EPS transport protein family (accession number TIGR01005). Most of these genes are orthologs of $S$. meliloti genes required for the synthesis of precursors and the repeating unit, as well as decoration, polymerization, export, and degradation of EPS I. exoR, exoS, and exoX encode putative regulators of polysaccharide synthesis (Becker et al. 2002; Janczarek 2011). Orthologs of the S. meliloti $1021 \mathrm{wga}, w g c, w g d, w g e$, and $w g g$ genes, which are involved in the production of EPS II, have not been found in the $S$. fredii $\mathrm{HH} 103$ genome.

Little is known about the regulation of surface polysaccharide production in S. fredii HH103. The MucR/RosR protein has been described as another transcriptional regulator involved in EPS production in S. meliloti and Rhizobium leguminosarum (Janczarek 2011). HH103 possesses two copies of the mucR gene, mucRl (chromosomal, SFHH103_00694, 143 aa) and mucR2 (psfHH103d_392, 142 aa), which are 75\% identical on the amino acid level. MucRl of HH103 and MucR of S. meliloti 1021 are very similar (97\% identity).

Flavonoids influence surface polysaccharide production in both HH103 and NGR234, but curiously, the changes are different. In spite of harboring the same exo cluster and producing identical EPS (Rodríguez-Navarro et al. 2014), the presence of genistein or luteolin does not affect EPS production in NGR234 (our unpublished results) but results in a nonmucoid phenotype in HH103 (Vinardell et al. 2004b). The reason for this phenotype remains to be elucidated.

In NGR234, the presence of inducing flavonoides affects the production of two surface polysaccharides. First, it provokes a decrease in $\mathrm{K}$-antigen production in a process mediated by nodD1 and $y 4 g M$ (Simsek et al. 2009). Second, it leads to the production of a rhamnose-rich LPS through the induction of the fixF, $r g p F$, and $w b g A$ genes (Ardissone et al. 2011). Neither $y 4 g M$, nor $f i x F, \operatorname{rgpF}$, nor $w b g A$ are present in HH103. Consistent with this observation, in $\mathrm{HH} 103$ the presence of flavonoids does not affect the amount of KPS produced (Hidalgo et al. 2010) and does not induce the synthesis of novel species of LPS (Fig. 6).

\section{Nitrogen fixation genes.}

Rhizobia show a high plasticity both in the composition of the nif regulon and one or more of the regulatory pathways controlling its expression (Masson-Boivin et al. 2009). The $S$. fredii HH103 set of nif genes is the same as in NGR234: nifWS (psfHH103d_206,207), nifZ (psfHH103d_220), nifBA (psfHH103d_222,223), nifQ (psfHH103d_233), nifHDKENX (psfHH103d_238 to 243), and nifH2D2K2 (psfHH103d_302 to 304). Interestingly, the NifX protein from HH103 is much longer (324 amino acid residues) than that present in most rhizobia (about 160 to 170 residues), including NGR234 (160 residues). In fact, the $\mathrm{HH} 103 \mathrm{NifX}$ protein is identical in its first 160 amino acid residues to NifX of NGR234 and 98\% identical to the conserved hypothetical protein encoded by NGR234_a01070, which is located downstream of the nifX gene. Thus, nif $X$ of $\mathrm{HH} 103$ seems to be the result of the fusion of two adjacent genes.

\section{Quorum sensing (QS) systems.}

In sinorhizobia, the QS systems TraI-TraR and SinI-SinR(-ExpR) have been described, with variations at the strain level (Downie 2010; Sanchez-Contreras et al. 2007). The analysis of the $S$. fredii $\mathrm{HH} 103$ genome reveals the presence of both QS systems. On the chromosome, the SFHH103_01571 and SFHH103_01572 genes encode a LuxR-like regulator and an $N$-acyl homoserine lactone ( $N$-AHL) synthase that are similar to SinR and SinI of S. meliloti 1021 (86\% and 90\% identity, respectively) and to NgrR and NgrI of S. fredii NGR234 (Schmeisser et al. 2009). Some S. meliloti strains, such as Rm41 (YP_006841949), SM11 (YP_005721901), 8530 (ABC88593), or RU11/001 (CDH87360), possess a second LuxR-like protein named ExpR, which, at least in strain 8530, interacts with the $N$-AHL produced by SinI, expanding the number of genes that are regulated by this autoinducer. In S. meliloti 1021 and 2011, the $\operatorname{expR}$ gene is interrupted by an insertion sequence (Pellock et al. 2002). In fact, the $\exp R$ gene is frequently disrupted in domesticated strains of $S$. meliloti, since this gene is responsible for growth restraint (Charoenpanich et al. 2014). A similar situation occurs in $S$. fredii. Strain NGR234 contains a complete $\operatorname{expR}$ gene, whereas both HH103 and USDA257 harbor a broken version of this gene. In strain USDA257 the expR gene is split by a point mutation into two ORF (AFL54305 and AFL54306). In HH103, there are two pieces corresponding to NGR_c32870 (SFHH103_03432 and SFHH103_03306) that are more than $100 \mathrm{~kb}$ distant on the chromosome, and each of the pieces is flanked by a copy of the same insertion sequence. In S. meliloti, the Sin system activates EPS and represses flagellum production. Most of the ExpR-binding sites identified in S. meliloti are also present in the genome of NGR234 (Charoenpanich et al. 2013), suggesting that at least part of the SinI-SinR-ExpR regulatory network is conserved between $S$. meliloti and $S$. fredii NGR234.

Another HH103 gene coding for an N-AHL synthase is located on pSfHH103d (psfHH103_478). The putative polypeptide is $98 \%$ identical to NGR234 TraI, which could be related to plasmid transfer regulation. However, the coding gene for the corresponding regulatory protein appears to be split into two putative ORF, psfHH103_463 and psfHH103_462, which code for 152- and 82-amino acid polypeptides containing the $N$-AHL- and DNA-binding domains, respectively, and that are 97 and $100 \%$ identical to the corresponding parts of the TraR protein of NGR234 (236 amino acids). Curiously, the same situation occurs in S. fredii USDA257, in which these two genes are

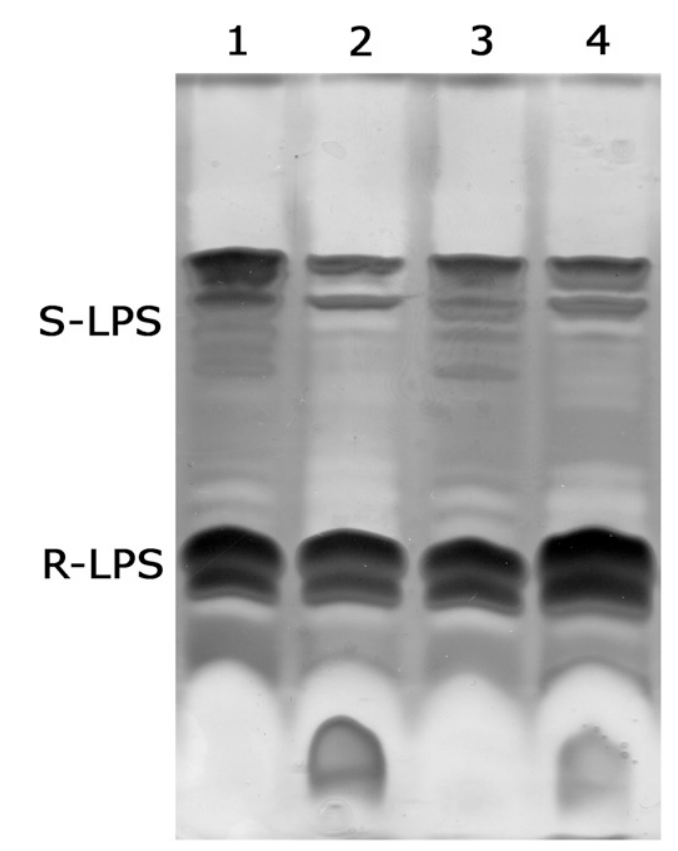

Fig. 6. Sodium dodecyl sulfate-polyacrylamide gel electrophoresis and silver staining of crude extracts of lipopolysaccharides (LPS) from Sinorhizobium fredii $\mathrm{HH} 103$ grown in the absence (lanes 1 and 3) or in the presence (lanes 2 and 4) of genistein. $S$. fredii $\mathrm{HH} 103$ was grown in tryptone yeast (lanes 1 and 2) and in $\mathrm{B}^{-}$(lanes 3 and 4) media (Spaink et al. 1992). The rough and smooth forms of LPS are indicated as R-LPS and S-LPS, respectively. 
named as traRl and traR2, respectively. In addition, HH103 contains a gene (psfHH103_651) coding for a 119-amino acid protein, which shows $69 \%$ identity to the N-terminal part of TraI. This gene, which is located immediately upstream of the pSfHH103d virB operon, is also present in USDA257 but not in NGR234.

In NGR234 several genes exist, which code for proteins potentially involved in degradation of $N$-AHL (Krysciak et al. 2011; Schmeisser et al. 2009), including lactonases (NGR_b01930, NGR_c03800, qsdR1, qsdR2, and $d l h R$ ), an acetaldehyde dehydrogenase (aldR), and a hydrolase (hitRhydR locus). With the exception of $d l h R$, HH103 carries orthologs of all these genes (SFHH103_06748, SFHH103_00448, SFHH103_06468, SFHH103_01489, SFHH103_02183, SFHH103_03790, and SFHH103_037905) that code for proteins at least $76 \%$ identical to their counterparts in NGR234.

Recently, an RNA-seq approach revealed that, in NGR234, $\Delta$ traI and $\Delta n g r I$ mutants, several hundred genes are differentially expressed, including genes involved in flagellar biosynthesis and EPS synthesis (Krysciak et al. 2014). Thus, the differences found in the QS systems of strains HH103 and USDA257 with regard to NGR234 could be relevant for traits such as motility and surface polysaccharide production.
The genome of $S$. fredii $\mathrm{HH103}$ contains a number of genes related to protein secretion.

Rhizobia use different systems for the secretion of proteins, which modulate their interaction with host plants (Deakin and Broughton 2009; Krehenbrink and Downie 2008). S. fredii HH103 encodes type I to type IV secretion systems (Table 3 ). Using homology searches, no genes coding for a type VI secretion system were found. So far, only a few Sinorhizobium species including $S$. fredii USDA207 were reported to encode such a system (Sugawara et al. 2013). Likewise, proteins similar to known type $\mathrm{V}$ secretion transport units (Gawarzewski et al. 2013) were not identified. Gene clusters coding for type IV pili are located on the chromosome and plasmid psfHH103e. The chromosome also carries the genes for the Sec- and Tatdependent protein transport.

In rhizobia, the best characterized type I transporter is the PrsDE system (Krehenbrink and Downie 2008). It has a wide substrate range of at least 12 different proteins, including NodO, that could influence nodulation. The prtD and prtE genes of Erwinia chrysanthemi are required for the export of two extracellular proteases (Delepelaire and Wandersman 1991). For HH103, no functional data are available for the PrsDE and the PrtDE systems. A large group of type I substrates are the RTX-proteins,

Table 3. Genes related to protein secretion

\begin{tabular}{|c|c|c|}
\hline System & Gene identification & Localization \\
\hline \multicolumn{3}{|l|}{ Type I secretion } \\
\hline tolC & SFHH103_01236 & Chromosome \\
\hline prtDE & SFHH103_03015 to SFHH103_03016 & Chromosome \\
\hline prsDE & SFHH103_06228 to SFHH103_06229 & pSfHH103e \\
\hline Type II secretion & & Chromosome \\
\hline gspDEFGHIJKLM gspO & SFHH103_02678 to SFHH103_02688 & \\
\hline \multicolumn{3}{|l|}{ Type III secretion (T3SS) } \\
\hline T3SS-I & & pSfHH103d \\
\hline $\begin{array}{l}\text { rhcC1 rhcC2 nolB rhcJ nolU rhcL rhcN } \\
\text { rhcQRSTUV ttsI nopA }\end{array}$ & psfHH103d_323 to psfHH103d_352 & \\
\hline \multicolumn{3}{|l|}{ Truncated T3SS } \\
\hline T3SS-II & & pSfHH103e \\
\hline rhcC2 rhcQRSTUV & SFHH103_04955 to SFHH103_04964 & \\
\hline \multicolumn{3}{|l|}{ Type IV secretion (T4SS) } \\
\hline T4SS-I & & pSfHH103d \\
\hline virB1-B11 & psfHH103d_637 to psfHH103d_647 & \\
\hline T4SS-II & & pSfHH103e \\
\hline virB1-B11 & SFHH103_06274 to SFHH103_06285 & \\
\hline \multicolumn{3}{|l|}{ Truncated T4SS } \\
\hline T4SS-III & & pSfHH103c \\
\hline virB2-6 virB8-11 virD4 & SFHH103_04078 to SFHH103_04089 & \\
\hline Conjugal transfer region (T4) & & pSfHH103d \\
\hline traI traM traR & psfHH103d_461 to psfHH103d_478 & \\
\hline \multicolumn{3}{|l|}{ trbBCDEFGHtrbIJKL } \\
\hline Twin-arginine translocation (TAT) system & & Chromosome \\
\hline tat $A$, tatB, tat $C$ & SFHH103_01251 to 01253 & \\
\hline \multicolumn{2}{|l|}{ Secretion system } & Chromosome \\
\hline $\sec D$ & SFHH103_00220 & \\
\hline $\sec E$ & SFHH103_01061 & \\
\hline $\sec Y$ & SFHH103_01095 & \\
\hline $\sec G$ & SFHH103_01162 & \\
\hline $\sec A$ & SFHH103_02600 & \\
\hline $\sec B$ & SFHH103_03504 & \\
\hline yajC & SFHH103_01260 & \\
\hline $\sec D / \mathrm{Sec} F$ & SFHH103_01261 & \\
\hline lebP & SFHH103_00760 & \\
\hline yidC & SFHH103_00082 & \\
\hline \multicolumn{2}{|l|}{ SRP (signal recognition particle) components } & Chromosome \\
\hline$f t s Y$ & SFHH103_03252 & \\
\hline$f f h$ & SFHH103_03247 & \\
\hline$f f s$ & SFHH103_02123 & \\
\hline \multicolumn{2}{|l|}{ Flagellar system gene cluster } & Chromosome \\
\hline $\begin{array}{l}\text { flaABCD flaF, fliEFG fliI fliLMN fliPQR, } \\
\text { flgABCDEFGHIJKL, flhA-B, flbT, } \\
\text { motABCD }\end{array}$ & SFHH103_00303 to 00346 & \\
\hline
\end{tabular}


which contain the so-called GG-repeats GGxGxDxxx (Linhartová et al. 2010). A genome-wide search for proteins containing the GGrepeat motif in $S$. fredii $\mathrm{HH} 103$ unveiled 60 proteins containing at least one repeat. A subsequent PsortB (Yu et al. 2010) analysis of these sequences reduced the number of putative type I secretion system substrates to 17 (Table 4). One additional candidate (SFHH103_05707) was identified by its similarity to RL2412 (30\% identity within 355 amino acid residues) from $R$. leguminosarum bv. viciae, which is a secreted protein (Krehenbrink and Downie 2008).

A functional type III secretion system gene cluster (T3SS-I) (de Lyra et al. 2006) is located on the symbiotic plasmid psfHH103d (Table 3). In this region, several Rhizobium conserved (rhc) genes (pSFHH103d 324 to pSFHH103d 352) genes coding for secreted effectors and a gene for the putative transcriptional regulator TtsI (psfHH103d_323) are present. This cluster matches the organization of the symbiotically relevant T3SS-I gene cluster of NGR234 and of USDA257 (Fig. 7). A second T3SS gene cluster (T3SS-II), which is obviously rearranged, was identified on plasmid psfHH103e (Fig. 7). Some genes putatively coding for components of the secretion apparatus ( $r h c R S T U V$ and $r h c C 2$ ) are present, but others, e.g., $r h c N$, coding for the cytoplasmic ATPase, as well as rhcQLJ and $r h c C 1$, are missing. It is well-established that, depending on the host, the T3SS-I has a beneficial or detrimental effect on symbiosis (de Lyra et al. 2006). In contrast, no data are available

Table 4. Putative type I secreted proteins

\begin{tabular}{lcc}
\hline Locus_tag & No. of GG-repeats & Conserved domain/description \\
\hline SFHH103_00407 & 26 & Calcium-binding protein, RTX toxin-like \\
SFHH103_00611 & 6 & Calcium-binding protein, RTX toxin-like \\
SFHH103_01246 & 1 & Sporulation-related domain \\
SFHH103_01633 & 6 & Hypothetical glycine-rich protein \\
SFHH103_01863 & 11 & Calcium-binding protein, RTX toxin-like \\
SFHH103_01864 & 14 & Calcium-binding protein, RTX toxin-like \\
SFHH103_01865 & 31 & Calcium-binding protein, RTX toxin-like \\
SFHH103_01866 & 24 & Calcium-binding protein, RTX toxin-like \\
SFHH103_02192 & 25 & Calcium-binding protein, RTX toxin-like \\
SFHH103_02387 & 2 & VCBS repeat protein \\
SFHH103_02654 & 5 & Calcium-binding protein, RTX toxin-like \\
SFHH103_03013 & 5 & Hypothetical protein \\
SFHH103_03856 & 1 & Hypothetical protein \\
SFHH103_05322 & 4 & Zinc-dependent metalloprotease \\
SFHH103_05541 & 1 & Beta-glucanase, calcium-binding protein \\
SFHH103_05750 & 14 & Calcium-binding protein, RTX toxin-like \\
SFHH103_05707 & 0 & Hypothetical protein \\
SFHH103_05957 & 11 & Calcium-binding protein, RTX toxin-like \\
\hline
\end{tabular}
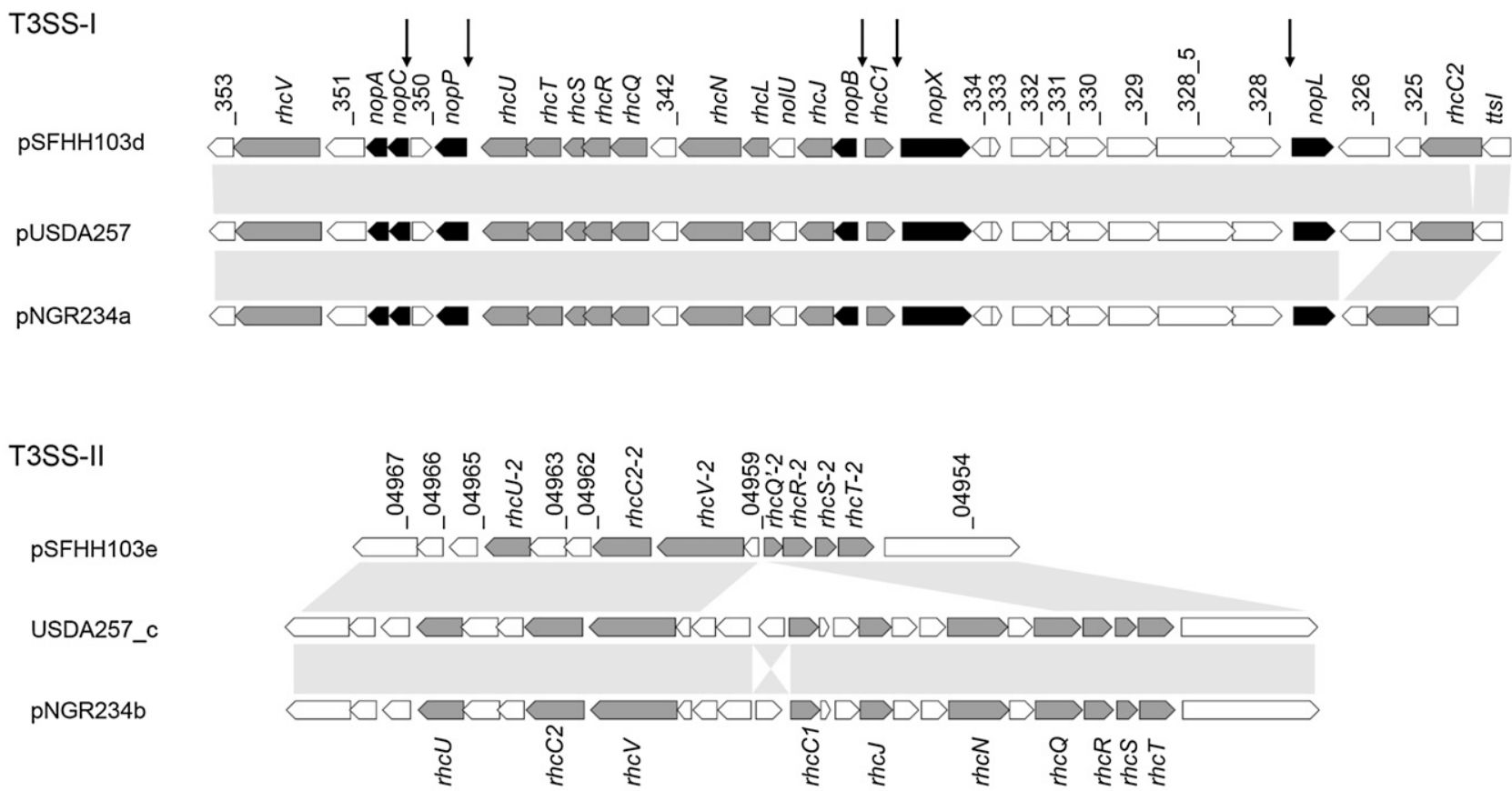

Fig. 7. Comparison of the type III secretion system (T3SS) gene clusters of the Sinorhizobium fredii strains HH103, NGR234, and USDA257. Genes encoding nodulation outer proteins (Nop) are indicated in black. Effector proteins encoded outside the T3SS-I gene cluster are not shown. Genes encoding Rhizobium conserved $(r h c)$ proteins are shaded in gray. $t t s I$ encodes a conserved transcriptional activator. For HH103, the positions of $t t s$ box sequences are indicated by vertical arrows. Genes conserved in the three $S$. fredii strains are connected by gray blocks. The function of the T3SS-II gene cluster is still unknown. Nop are not known for this system. Open reading frames are shown for HH103 (pSFHH103d_353 to pSFHH103d_327 and SFHH103_04967 to SFHH103_04954), for NGR234 (NGR234_447 to NGR234_475 and NGR_b22770 to NGR_b23010) and for USDA257 (USDA257_p02630 to USDA257_p02960 and USDA257_c21430 to USDA257_c21670). For reasons of clarity, not all locus tags or gene names are indicated. For the conserved rhc genes of the T3SS-II gene cluster, we suggest the extension -2 , e.g., $r h c U-2$. 
for the T3SS-II of HH103. For NGR234, no symbiotic defect was found for a T3SS-II mutant (Schmeisser et al. 2009), although genes belonging to this locus are up-regulated in Vigna unguiculata and Leucaena leucocephala NGR234 bacteroids (Li et al. 2013).

Several secreted effectors of $S$. fredii $\mathrm{HH} 103$ were identified previously (de Lyra et al. 2006; López-Baena et al. 2008; Rodrigues et al. 2007). In addition, we identified the putative effector protein GunA (locus_tag psfHH103d_292), which might be a glycosylhydrolase. GunA is highly similar to GunA2 (93\% identity on the amino acid level over the entire length) of Bradyrhizobium japonicum USDA110. In this strain, GunA2 is a secreted protein (Süss et al. 2006). Remarkably, gunA was not found in NGR234 or USDA257. Most of the known secreted effector proteins are encoded on the symbiotic plasmid psfHH103d. The genome sequence revealed that the effector NopM, an E3 ubiquitin protein ligase-like protein, is encoded by two identical gene copies, nopM (psfHH103d_90) on psfHH103d and nopM2 (SFHH103_04201) on plasmid psfHH103c. Interestingly, NopI, which shares about $45 \%$ identity with NopP (encoded by psfHH103d_349), is also encoded on plasmid psfHH103c (locus_tag SFHH103_04163). An ORF that codes for a protein $99 \%$ identical to NopI is present in USDA257 (CP003565, 446 to 1,303) but not in NGR234. An interesting approach for the identification of putative effector proteins was used by Kimbrel et al. (2013). They fused N-terminal parts of Sinorhizobium fredii proteins with the AvrRpt2 effector of Pseudomonas syringae pv. tomato lacking its N-terminal secretion signal. By infiltration of Arabidopsis leaves with a $P$. syringae strain expressing the fusion proteins, they identified 13 and 15 effector candidates for USDA257 and NGR234, respectively.

Genes or operons coding for symbiosis-related T3SS genes and effectors in rhizobia are preceded by a conserved promoter motif, the $t t s$ box (Krause et al. 2002; López-Baena et al. 2008; Okazaki et al. 2009; Wassem et al. 2008; Zehner et al. 2008). A genome-wide search revealed the presence of more than $40 \mathrm{tts}$ box-like sequences, 18 of which are in intergenic regions upstream of ORFs (Supplementary Table S4), with the majority (12) found in the symbiotic plasmid psfHH103d. The newly identified genes nopI, nopM2, and gunA are also preceded by $t t s$ box sequences.

$S$. fredii $\mathrm{HH} 103$ contains a number of genes related to type IV secretion systems (Table 3). Two very similar virB clusters (virBl and virB11) are located on plasmids psfHH103d and psfHH103e. A third virB cluster with a slightly different genetic organization is located on plasmid psfHH103c and is the only vir cluster that also contains a virD4/traG-like gene (locus_tag SFHH103_04078). However, further VirD4/TraG-like proteins are encoded on plasmids psfHH103a1 (SFHH103_03975), psfHH103b (SFHH103_03995), psfHH103d (psfHH103d_56), and psfHH103e (SFHH103_06248). A gene cluster coding for a conjugal type IV system is also located on the symbiotic plasmid psfHH103d. The organization of the genes is similar to the traltrb gene cluster of the symbiotic plasmid of NGR234. In contrast, the symbiotic plasmid of NGR234 does not contain a virB-like cluster. Whether any of the type IV secretion systems of $\mathrm{HH} 103$ are involved in symbiotic interactions remains to be elucidated.

\section{Concluding remarks.}

The rhizobial-legume symbiosis is of primary importance in nature and in agriculture. However, despite the importance of symbiotic nitrogen fixation, only a small number of rhizobial strains have been completely sequenced, representing fewer than $1 \%$ of the complete bacterial genomes available in 2012 (Black et al. 2012). The study of the genomes of both partners (legumes and rhizobia) will facilitate our understanding of the underlying molecular mechanisms that operate in this symbiosis and will, eventually, help us to enhance its implementation in agriculture. Comparative genomics can be a valuable approach for capturing specificities and generalities of each genome. The comparison of the symbiosis-related genes as well as of the QS systems present in strains NGR234, USDA257, and $\mathrm{HH} 103$ revealed significant differences. These features clearly merit further analyses, as they could be related to the different host ranges and to different symbiotic behaviors with soybean, one of the most important crops used worldwide. In addition, whether these differences arose in nature or subsequent to isolation and domestication is an important consideration to be addressed in the future.

\section{MATERIALS AND METHODS}

\section{Microbiological techniques and plant assays.}

Sinorhizobium fredii strains were grown at $28^{\circ} \mathrm{C}$ on $\mathrm{TY}$ (Beringer 1974) or B ${ }^{-}$media (Spaink et al. 1992) and Escherichia coli was cultured on Luria-Bertani medium (Sambrook et al. 1989) at $37^{\circ} \mathrm{C}$. When required, the media were supplemented with the appropriate antibiotics as described by Vinardell et al. (2004a). Plasmids were transferred from E. coli to rhizobia by conjugation as described by Simon (1984). For studying IAA production, $S$. fredii $\mathrm{HH} 103$ was grown with RMS medium (Theunis et al. 2004), a modified rhizobial minimal medium in which succinate is used as carbon source instead of mannitol. The IAA level was analyzed as described by Ribeiro and Cardoso (2012).

LPS extraction from bacterial cultures grown on solid TY medium, separation of LPS by SDS-polyacrylamide gel electrophoresis, and their detection by silver staining were done as described previously (Buendía-Clavería et al. 2003).

Nodulation assays on Glycine max cv. Williams (soybean), Vigna unguiculata (cowpea), and Cajanus cajan (pigeon pea) were performed as described (Crespo-Rivas et al. 2007; Hidalgo et al. 2010).

\section{Sequencing and automated assembly of $S$. fredii $\mathrm{HH} 103$ genome.}

The Genome Sequencer FLX (GS FLX) system (454 Life Sciences, a Roche company, Branford, CT, U.S.A.) has been used for pyrosequencing of the $S$. fredii $\mathrm{HH} 103$ strain. Two different library preparation and sequencing protocols as well as sequencing chemistries were used on the GS FLX platform as described by Schwientek et al. 2011. (i) Standard sequencing chemistry with long paired end (PE) protocol: The DNA fragment size for the PE library construction of $S$. fredii was $1,782 \mathrm{bp} \pm 445$. Altogether 1.5 runs were sequenced. (ii) Titanium sequencing chemistry with whole-genome shotgun (WGS) protocol. The DNA fragment size for the WGS library construction was 500 to $800 \mathrm{bp}$, all together a quarter of a picotiter plate.

The automated assembly of all $S$. fredii $\mathrm{HH} 103$ reads generated by the GS FLX platform was performed with the Newbler assembler software (gsAssembler version 2.0.01.14; 454 Life Sciences). For the assembly process, standard settings were used.

\section{Construction of a $S$. fredii $\mathrm{HH} 103$ fosmid clone library and genome finishing.}

To enable gap closure and assembly validation, a fosmid library was constructed by IIT Biotech GmbH (Bielefeld, Germany), using the EpiFOS fosmid library production kit (Epicentre, Madison, WI, U.S.A.). Fosmid insert end sequencing was carried out on an ABI 3730xl DNA analyzer by IIT Biotech $\mathrm{GmbH}$. Remaining gaps in the assembled sequence were closed by primer walking on fosmid clones (IIT Biotech $\mathrm{GmbH}$ ) and PCR amplicon sequencing in cases where gaps are 
not covered by fosmid clones, as described by Schwientek et al. 2012 and Heinl et al. 2012. For this purpose, a HH103 cosmid library (Vinardell et al. 2004b) was also used. Due to a high abundance of repeated sequences, three gaps remain in the symbiotic plasmid pSfHH103d. In brief, the assembly software package Consed (Gordon et al. 1998, 2001) was utilized to add the finishing reads to the assembled 454 sequences and to design primers for finishing reads.

\section{Plasmid tagging.}

Recombinant DNA techniques were applied according to the general protocols of Sambrook and associates (1989). PCR amplifications were done as described (Vinardell et al. 2004b). For amplification of large DNA fragments, the Velocity DNA polymerase from Bioline (Taunton, MA, U.S.A.) was used according to the manufacturer's instructions.

In order to tag plasmids pSfHH103a1, pSfHH103b, or pSfHH103c with the sacBR genes of Bacillus subtilis a 2-kb PCR fragment containing a $B g l I I$ restriction site located in its center was PCR-amplified from each plasmid. Primer pairs used were $\mathrm{pSfHHa} 1-\mathrm{F} / \mathrm{R}, \mathrm{pSfHHb}-\mathrm{F} / \mathrm{R}$, and $\mathrm{pSfHHc}-\mathrm{F} / \mathrm{R}$ (Supplementary Table S3). The fragments obtained were subcloned into plasmid pGEM-T-easy for propagation, were excised as EcoRI fragments, and were subcloned into the unique EcoRI restriction site of plasmid pSUP202 (a suicide vector for rhizobia that is resistant to ampicillin, tetracycline $\left[\mathrm{Tc}^{\mathrm{r}}\right]$, or chloramphenicol $\left[\mathrm{Cm}^{\mathrm{r}}\right.$;]) (Simon et al. 1983), thereby inactivating the $\mathrm{Cm}^{\mathrm{r}}$ gene. The resulting plasmids were pMUS1116, pMUS1117, and pMUS1118. A 3.8-kb BamHI fragment from plasmid pUM24 (Ried and Collmer 1987) containing the $n p t I$ gene (kanamycin resistant $\left[\mathrm{Km}^{\mathrm{r}}\right]$ ) and the sacBR genes from Bacillus subtilis was subcloned into the unique $B g l I I$ restriction site of plasmids pMUS1116, pMUS1117, and pMUS1118, generating plasmids pMUS1124, pMUS1125, and pMUS1126, respectively. These plasmids were individually introduced into $S$. fredii $\mathrm{HH} 103$ rifampicinresistant $\left(\right.$ Rif $\left.^{\mathrm{r}}\right)$ genes by conjugation. $\mathrm{Rif}^{\mathrm{r}} \mathrm{Km}^{\mathrm{r}} \mathrm{Tc}^{\mathrm{s}}$ transconjugants were selected in order to isolate double recombinants in which the nptI-sacBR genes had been integrated into plasmids pSfHH103a1, pSfHH103b, or pSfHH103c, resulting in strains SVQ698 (=HH103 Rif ${ }^{\mathrm{r}}$ pSfHH103a1::nptIsacBR), SVQ699 (=HH103 Rif ${ }^{\mathrm{r}}$ pSfHH103b:: nptIsacBR), and SVQ700 (=HH103 Rif $^{\mathrm{r}}$ pSfHH103c:: nptIsacBR). The integrations were verified by PCR, using the same primer pairs employed for the initial amplification of the 2-kb fragments. Strains SVQ698, SVQ699, and SVQ700 were grown in liquid TY medium, were subcultured in this medium for 30 generations, and were then plated onto TY medium supplemented with Rif and $12.5 \%$ (wt/vol) sucrose. Several SVQ698 and SVQ700 sucrose-resistant clones that showed no amplifiable fragments with primer pairs SfHHa1-F/R and pSfHHc-F/R, respectively, were obtained. These were tested with additional primer pairs that annealed at different locations of plasmid pSfHH103al and pSfHH103c. Clones that showed no amplification with any of the primer pairs were further tested for the absence of plasmids pSfHH103a1 or pSfHH103c by plasmid DNA extraction and restriction as well as PCR analyses. In this way, strains SVQ736 (=HH103 Rif $\left.{ }^{\mathrm{r}} \mathrm{pSfHH} 103 \mathrm{a1}{ }^{-}\right)$ and SVQ737 $\left(=\mathrm{HH} 103 \mathrm{Rif}^{\mathrm{r}} \mathrm{pSfHH} 103 \mathrm{c}^{-}\right)$were obtained and were selected for further studies. The absence of pSfHH103c in strain SVQ737 was also confirmed by plasmid profile visualization (data not shown) as described previously (Vinardell et al. 2004b). Although we analyzed 66 different sucrose-resistant derivatives of SVQ699, none of them had lost plasmid pSfHH103b. In all plasmids, small DNA fragments including the $n p t I-s a c B R$ cassette were deleted (data not shown).

\section{Bioinformatics.}

GenDB software was used for manual annotation of the S. fredii HH103 genome (Meyer et al. 2003). Comparative analysis between the genomes of $\mathrm{HH} 103$ and other sinorhizobia were performed with EDGAR software (Blom et al. 2009), based on an all-against-all comparison of protein sequences using BLASTP (Altschul et al. 1990). All hits were normalized in relation to the best score possible, i.e., the score of a hit of the query gene against itself, resulting in score ratio values (SRV) as described by Lerat et al. (2003). Genes were considered to be orthologous if both unidirectional BLASTP hits of a reciprocal best BLAST hit showed a SRV higher than 0.31. The Artemis comparison tool (ACT) (Carver et al. 2005) and WebACT were used with blastN program default options.

Primers were designed using the GeneFisher2 utility and were provided by Integrated Data Technologies. For sequence comparisons and similarity analyses, the BLAST suite of NCBI (Johnson et al. 2008) was used. Conserved motifs of putatively type I secreted proteins were identified by the program MOTIF, developed by the Kyoto University Bioinformatics Center. The KEGG database (Kanehisa et al. 2014) for Sinorhizobium fredii HH103 was analyzed with the pattern "G-G-X-G-X-D-X-X-X" (Delepelaire 2004). Further analyses of putatively secreted proteins were done with the programs PSORTb version 3.0.2. (Yu et al. 2010) and SMART (Letunic et al. 2012). The analysis of intergenic regions for $t t s$ box-like sequences was carried out with the program fuzznuc of the EMBOSS package (Rice et al. 2000). The search pattern was $\{\mathrm{t}\}$ tcagn[tg][tcg]n[ta]n[ga]nna [gat]n(11)a. Hits were selected based on their conservation to known $t$ ts box sequences (Zehner et al. 2008) as well as their location in intergenic regions upstream of open reading frames.

\section{ACKNOWLEDGMENTS}

This work was supported by grant $0313805 \mathrm{~A}$ from the Federal Ministry of Education and Research, Germany, by grants BIO2008-05736-C02-01/02 and BIO2011-30229-C01 from the Spanish Ministry of Science and Innovation, and by grant P11-CVI-7500 from the Andalusian Government. We thank Á. Hidalgo and R. Gutiérrez-Alcántara for technical assistance and F. G. Eikmeyer and D. Wibberg for bioinformatics support.

\section{LITERATURE CITED}

Altschul, S. F., Gish, W., Miller, W., Myers, E. W., and Lipman, D. J. 1990. Basic local alignment search tool. J. Mol. Biol. 215:403-410.

Ardissone, S., Noel, K. D., Klement, M., Broughton, W. J., and Deakin, W. J. 2011. Synthesis of the flavonoid-induced lipopolysaccharide of Rhizobium sp. strain NGR234 requires rhamnosyl transferases encoded by genes $r g p F$ and $w b g A$. Mol. Plant-Microbe Interact. 24:1513-1521.

Barnett, M. J., Fisher, R. F., Jones, T., Komp, C., Pia Abola, A., BarloyHubler, F., Bowser, L., Capela, D., Galibert, F., Gouzy, J., Gurjal, M., Hong, A., Huizar, L., Hyman, R. W., Kahn, D., Kahn, M. L., Kalman, S., Keating, D. H., Palm, C., Peck, M. C., Surzycki, R., Wells, D. H., Yeh, K.-C., Davis, R. W., Federspiel, N. A., and Long, S. R. 2001. Nucleotide sequence and predicted functions of the entire Sinorhizobium meliloti pSymA megaplasmid. Proc. Natl. Acad. Sci. U.S.A. 98:9883-9888.

Bec-Ferté, M. P., Krishnan, H. B., Promé, D., Savagnac, A., Pueppke, S. G., and Promé, J.-C. 1994. Structures of nodulation factors from the nitrogen-fixing soybean symbiont Rhizobium fredii USDA257. Biochemistry 33:11782-11788.

Becker, A., Rüberg, S., Baumgarth, B., Bertram-Drogatz, P. A., Quester, I., and Pühler, A. 2002. Regulation of succinoglycan and galactoglucan biosynthesis in Sinorhizobium meliloti. J. Mol. Microbiol. Biotechnol. 4:187-190.

Beringer, J. E. 1974. R factor transfer in Rhizobium leguminosarum. J. Gen. Microbiol. 84:188-198.

Black, M., Moolhuijzen, P., Chapman, B., Barrero, R., Howieson, J., Hungria, M., and Bellgard, M. 2012. The genetics of symbiotic nitrogen fixation: Comparative genomics of 14 rhizobia strains by resolution of protein clusters. Genes 3:138-166.

Blom, J., Albaum, S. P., Doppmeier, D., Pühler, A., Vorhölter, F. J., Zakrzewski, M., and Goesmann, A. 2009. EDGAR: A software framework for the comparative analysis of prokaryotic genomes. BMC Bioinformatics 10:154. 
Buendía-Clavería, A. M., Moussaid, A., Ollero, F. J., Vinardell, J. M., Torres, A., Moreno, J., Gil-Serrano, A. M., Rodríguez-Carvajal, M. A., Tejero-Mateo, P., Peart, J. L., Brewin, N. J., and Ruiz-Sainz, J. E. 2003. A purL mutant of Sinorhizobium fredii $\mathrm{HH} 103$ is symbiotically defective and altered in its lipopolysaccharide. Microbiology 149:1807-1818.

Carver, T. J., Rutherford, K. M., Berriman, M., Rajandream, M. A., Barrell, B. G., and Parkhill, J. 2005. ACT: The Artemis Comparison Tool. Bioinformatics 21:3422-3423.

Charoenpanich, P., Meyer, S., Becker, A., and McIntosh, M. 2013. Temporal expression program of quorum sensing-based transcription regulation in Sinorhizobium meliloti. J. Bacteriol. 195:3224-3236.

Charoenpanich, P., Soto, M. J., Becker, A., and McIntosh, M. 2014. Populations of Sinorhizobium meliloti maintain cooperative behavior through ExpR/quorum sensing induced lifestyle switch. Environ. Microbiol. Rep. 7:373-382.

Cheng, J., Sibley, C. D., Zaheer, R., and Finan, T. M. 2007. A Sinorhizobium meliloti minE mutant has an altered morphology and exhibits defects in legume symbiosis. Microbiology 153:375-387.

Crespo-Rivas, J. C., Margaret, I., Pérez-Montaño, F., López-Baena, F. J., Vinardell, J. M., Ollero, F. J., Moreno, J., Ruiz-Sainz, J. E., and BuendíaClavería, A. M. 2007. A pyrF auxotrophic mutant of Sinorhizobium fredii $\mathrm{HH} 103$ impaired in its symbiotic interactions with soybean and other legumes. Int. Microbiol. 10:169-176.

Crespo-Rivas, J. C., Margaret, I., Hidalgo, A., Buendía-Clavería, A. M., Ollero, F. J., López-Baena, F. J., del Socorro Murdoch, P., RodríguezCarvajal, M. A., Soria-Díaz, M. E., Reguera, M., Lloret, J., Sumpton, D. P., Mosely, J. A., Thomas-Oates, J. E., van Brussel, A. A. N., Gil-Serrano, A., Vinardell, J. M., and Ruiz-Sainz, J. E. 2009. Sinorhizobium fredii $\mathrm{HH} 103$ cgs mutants are unable to nodulate determinate- and indeterminate nodule-forming legumes and overproduce an altered EPS. Mol. Plant-Microbe Interact. 22:575-588.

D'Haeze, W., and Holsters, M. 2002. Nod factor structures, responses, and perception during initiation of nodule development. Glycobiology 12: 79R-105R.

de Lyra, M. C. C. P., López-Baena, F. J., Madinabeitia, N., Vinardell, J. M., Espuny, M. R., Cubo, M. T., Bellogin, R. A., Ruiz-Sainz, J. E., and Ollero, F. J. 2006. Inactivation of the Sinorhizobium fredii $\mathrm{HH} 103$ rhcJ gene abolishes nodulation outer proteins (Nops) secretion and decreases the symbiotic capacity with soybean. Int. Microbiol. 9:125-133.

Deakin, W. J., and Broughton, W. J. 2009. Symbiotic use of pathogenic strategies: Rhizobial protein secretion systems. Nat. Rev. Microbiol. 7: 312-320.

Delepelaire, P. 2004. Type I secretion in gram-negative bacteria. Biochim. Biophys. Acta 1694:149-161.

Delepelaire, P., and Wandersman, C. 1991. Characterization, localization and transmembrane organization of the three proteins PrtD, PrtE and PrtF necessary for protease secretion by the gram-negative bacterium Erwinia chrysanthemi. Mol. Microbiol. 5:2427-2434.

diCenzo, G., Milunovic, B., Cheng, J., and Finan, T. M. 2013. The tRNA ${ }^{\text {arg }}$ gene and engA are essential genes on the 1.7-Mb pSymB megaplasmid of Sinorhizobium meliloti and were translocated together from the chromosome in an ancestral strain. J. Bacteriol. 195:202-212.

diCenzo, G. C., MacLean, A. M., Milunovic, B., Golding, G. B., and Finan, T. M. 2014. Examination of prokaryotic multipartite genome evolution through experimental genome reduction. PLoS Genet. 10:e1004742.

Dowdle, S. F., and Bohlool, B. B. 1985. Predominance of fast growing Rhizobium japonicum in a soybean field in the People's Republic of China. Appl. Environ. Microbiol. 50:1171-1176.

Downie, J. A. 2010. The roles of extracellular proteins, polysaccharides and signals in the interactions of rhizobia with legume roots. FEMS (Fed. Eur. Microbiol. Soc.) Microbiol. Rev. 34:150-170.

Galibert, F., Finan, T. M., Long, S. R., Pühler, A., Abola, P., Ampe, F., Barloy-Hubler, F., Barnett, M. J., Becker, A., Boistard, P., Bothe, G., Boutry, M., Bowser, L., Buhrmester, J., Cadieu, E., Capela, D., Chain, P., Cowie, A., Davis, R. W., Dréano, S., Federspiel, N. A., Fisher, R. F., Gloux, S., Godrie, T., Goffeau, A., Golding, B., Gouzy, J., Gurjal, M., Hernandez-Lucas, I., Hong, A., Huizar, L., Hyman, R. W., Jones, T., Kahn, D., Kahn, M. L., Kalman, S., Keating, D. H., Kiss, E., Komp, C., Lelaure, V., Masuy, D., Palm, C., Peck, M. C., Pohl, T. M., Portetelle, D., Purnelle, B., Ramsperger, U., Surzycki, R., Thébault, P., Vandenbol, M., Vorhölter, F. J., Weidner, S., Wells, D. H., Wong, K., Yeh, K. C., and Batut, J. 2001. The composite genome of the legume symbiont Sinorhizobium meliloti. Science 293:668-672.

Gawarzewski, I., Smits, S. H., Schmitt, L., and Jose, J. 2013. Structural comparison of the transport units of type V secretion systems. Biol. Chem. 394:1385-1398.

Gil-Serrano, A. M., Franco-Rodríguez, G., Tejero-Mateo, P., ThomasOates, J., Spaink, H. P., Ruiz-Sainz, J. E., Megías, M., and Lamrabet, Y.
1997. Structural determination of the lipo-chitin oligosaccharide nodulation signals produced by Rhizobium fredii HH103. Carbohydr. Res. 303:435-443.

Gordon, D., Abajian, C., and Green, P. 1998. Consed: A graphical tool for sequence finishing. Genome Res. 8:195-202.

Gordon, D., Desmarais, C., and Green, P. 2001. Automated finishing with autofinish. Genome Res. 11:614-625.

Harrison, P. W., Lower, R. P., Kim, N. K., and Young, J. P. 2010. Introducing the bacterial 'chromid': Not a chromosome, not a plasmid. Trends Microbiol. 18:141-148.

Heinl, S., Wibberg, D., Eikmeyer, F., Szczepanowski, R., Blom, J., Linke, B., Goesmann, A., Grabherr, R., Schwab, H., Pühler, A., and Schlüter, A. 2012. Insights into the completely annotated genome of Lactobacillus buchneri CD034, a strain isolated from stable grass silage. J. Biotechnol. 161:153-166.

Heron, D. S., and Pueppke, S. G. 1984. Mode of infection, nodulation specificity, and indigenous plasmids of 11 fast-growing Rhizobium japonicum strains. J. Bacteriol. 160:1061-1066.

Hidalgo, A., Margaret, I., Crespo-Rivas, J. C., Parada, M., Murdoch, P. S., López, A., Buendía-Clavería, A. M., Moreno, J., Albareda, M., GilSerrano, A. M., Rodríguez-Carvajal, M. A., Palacios, J. M., Ruiz-Sainz, J. E., and Vinardell, J. M. 2010. The rkpU gene of Sinorhizobium fredii $\mathrm{HH} 103$ is required for bacterial K-antigen polysaccharide production and for efficient nodulation with soybean but not with cowpea. Microbiology 156:3398-3411.

Jabbouri, S., Fellay, R., Talmont, F., Kamalaprija, P., Burger, U., Relić, B., Promé, J. C., and Broughton, W. J. 1995. Involvement of nodS in $\mathrm{N}$-methylation and nodU in 6-O-carbamoylation of Rhizobium sp. NGR234 Nod factors. J. Biol. Chem. 270:22968-22973.

Jabbouri, S., Relić, B., Hanin, M., Kamalaprija, P., Burger, U., Promé, D., Promé, J. C., and Broughton, W. J. 1998. nolO and noeI (HsnIII) of Rhizobium sp. NGR234 are involved in 3-O-carbamoylation and 2-Omethylation of Nod factors. J. Biol. Chem. 273:12047-12055.

Janczarek, M. 2011. Environmental signals and regulatory pathways that influence exopolysaccharide production in rhizobia. Int. J. Mol. Sci. 12: 7898-7933.

Johnson, M., Zaretskaya, I., Raytselis, Y., Merezhuk, Y., McGinnis, S., and Madden, T. L. 2008. NCBI BLAST: A better web interface. Nucleic Acids Res. 36:W5-W9.

Kanehisa, M., Goto, S., Sato, Y., Kawashima, M., Furumichi, M., and Tanabe, M. 2014. Data, information, knowledge and principle: Back to metabolism in KEGG. Nucleic Acids Res. 42:D199-D205.

Kaneko, T., Nakamura, Y., Sato, S., Minamisawa, K., Uchiumi, T., Sasamoto, S., Watanabe, A., Idesawa, K., Iriguchi, M., Kawashima, K., Kohara, M., Matsumoto, M., Shimpo, S., Tsuruoka, H., Wada, T., Yamada, M., and Tabata, S. 2002. Complete genomic sequence of nitrogen-fixing symbiotic bacterium Bradyrhizobium japonicum USDA110. DNA Res. 9:189-197.

Kereszt, A., Kiss, E., Reuhs, B. L., Carlson, R. W., Kondorosi, A., and Putnoky, P. 1998. Novel rkp gene clusters of Sinorhizobium meliloti involved in capsular polysaccharide production and invasion of the symbiotic nodule: The $r k p K$ gene encodes a UDP-glucose dehydrogenase. J. Bacteriol. 180:5426-5431.

Kimbrel, J. A., Thomas, W. J., Jiang, Y., Creason, A. L., Thireault, C. A., Sachs, J. L., and Chang, J. H. 2013. Mutualistic co-evolution of type III effector genes in Sinorhizobium fredii and Bradyrhizobium japonicum. PLoS Pathog. 9:e1003204.

Krause, A., Doerfel, A., and Göttfert, M. 2002. Mutational and transcriptional analysis of the type III secretion system of Bradyrhizobium japonicum. Mol. Plant-Microbe Interact. 15:1228-1235.

Krehenbrink, M., and Downie, J. A. 2008. Identification of protein secretion systems and novel secreted proteins in Rhizobium leguminosarum bv. viciae. BMC Genomics 9:55.

Krishnan, H. B., Lewin, A., Fellay, R., Broughton, W. J., and Pueppke, S. G. 1992. Differential expression of nodS accounts for the varied abilities of Rhizobium fredii USDA257 and Rhizobium sp. strain NGR234 to nodulate Leucaena spp. Mol. Microbiol. 6:3321-3330.

Krysciak, D., Schmeisser, C., Preuss, S., Riethausen, J., Quitschau, M., Grond, S., and Streit, W. R. 2011. Involvement of multiple loci in quorum quenching of autoinducer I molecules in the nitrogen-fixing symbiont Rhizobium (Sinorhizobium) sp. strain NGR234. Appl. Environ. Microbiol. 77:5089-5099.

Krysciak, D., Grote, J., Rodriguez Orbegoso, M., Utpatel, C., Förstner, K. U., Li, L., Schmeisser, C., Krishnan, H. B., and Streit, W. R. 2014 RNA sequencing analysis of the broad-host-range strain Sinorhizobium fredii NGR234 identifies a large set of genes linked to quorum sensingdependent regulation in the background of a traI and ngrI deletion mutant. Appl. Environ. Microbiol. 80:5655-5671. 
Lamrabet, Y., Bellogín, R. A., Cubo, T., Espuny, R., Gil, A., Krishnan, H. B., Megias, M., Ollero, F. J., Pueppke, S. G., Ruiz-Sainz, J. E., Spaink, H. P., Tejero-Mateo, P., Thomas-Oates, J., and Vinardell, J. M. 1999. Mutation in GDP-fucose synthesis genes of Sinorhizobium fredii alters Nod factors and significantly decreases competitiveness to nodulate soybeans. Mol. Plant-Microbe Interact. 12:207-217.

Lerat, E., Daubin, V., and Moran, N. A. 2003. From gene trees to organismal phylogeny in prokaryotes: The case of the gamma-Proteobacteria. PLoS Biol. 1:E19.

Letunic, I., Doerks, T., and Bork, P. 2012. SMART 7: Recent updates to the protein domain annotation resource. Nucleic Acids Res. 40:D302-D305.

Li, Y., Tian, C. F., Chen, W. F., Wang, L., Sui, X. H., and Chen, W. X. 2013. High-resolution transcriptomic analyses of Sinorhizobium sp. NGR234 bacteroids in determinate nodules of Vigna unguiculata and indeterminate nodules of Leucaena leucocephala. PLoS ONE 8:e70531.

Linhartová, I., Bumba, L., Mašín, J., Basler, M., Osička, R., Kamanová, J., Procházková, K., Adkins, I., Hejnová-Holubová, J., Sadílková, L., Morová, J., and Sebo, P. 2010. RTX proteins: A highly diverse family secreted by a common mechanism. FEMS (Fed. Eur. Microbiol. Soc.) Microbiol. Rev. 34:1076-1112.

López-Baena, F. J., Vinardell, J. M., Pérez-Montaño, F., Crespo-Rivas, J. C., Bellogín, R. A., Espuny, M. R., and Ollero, F. J. 2008. Regulation and symbiotic significance of nodulation outer proteins secretion in Sinorhizobium fredii $\mathrm{HH} 103$. Microbiology 154:1825-1836.

Machado, D., Pueppke, S. G., Vinardell, J. M., Ruiz-Sainz, J. E., and Krishnan, H. B. 1998. Expression of nodD1 and nodD2 in Sinorhizobium fredii, a nitrogen-fixing symbiont of soybean and other legumes. Mol. Plant-Microbe Interact. 11:375-382.

Madinabeitia, N., Bellogín, R. A., Buendía-Clavería, A. M., Camacho, M., Cubo, T., Espuny, M. R., Gil-Serrano, A. M., Lyra, M. C., Moussaid, A., Ollero, F. J., Soria-Díaz, M. E., Vinardell, J. M., Zeng, J., and Ruiz-Sainz, J. E. 2002. Sinorhizobium fredii $\mathrm{HH} 103$ has a truncated nolO gene due to a -1 frameshift mutation that is conserved among other geographically distant $S$. fredii strains. Mol. Plant-Microbe Interact. 15:150-159.

Margaret, I., Becker, A., Blom, J., Bonilla, I., Goesmann, A., Göttfert, M., Lloret, J., Mittard-Runte, V., Rückert, C., Ruiz-Sainz, J. E., Vinardell, J. M., and Weidner, S. 2011. Symbiotic properties and first analyses of the genomic sequence of the fast growing model strain Sinorhizobium fredii HH103 nodulating soybean. J. Biotechnol. 155:11-19.

Margaret, I., Crespo-Rivas, J. C., Acosta-Jurado, S., Buendía-Clavería, A. M., Cubo, M. T., Gil-Serrano, A., Moreno, J., Murdoch, P. S., Rodríguez-Carvajal, M. A., Rodríguez-Navarro, D. N., Ruiz-Sainz, J. E., Sanjuán, J., Soto, M. J., and Vinardell, J. M. 2012. Sinorhizobium fredii HH103 rkp-3 genes are required for $\mathrm{K}$-antigen polysaccharide biosynthesis, affect lipopolysaccharide structure and are essential for infection of legumes forming determinate nodules. Mol. Plant-Microbe Interact. 25:825-838.

Margaret, I., Lucas, M. M., Acosta-Jurado, S., Buendía-Clavería, A. M., Fedorova, E., Hidalgo, Á., Rodríguez-Carvajal, M. A., RodriguezNavarro, D. N., Ruiz-Sainz, J. E., and Vinardell, J. M. 2013. The Sinorhizobium fredii $\mathrm{HH} 103$ lipopolysaccharide is not only relevant at early soybean nodulation stages but also for symbiosome stability in mature nodules. PLoS ONE 8:e74717.

Margaret-Oliver, I., Lei, W., Parada, M., Rodríguez-Carvajal, M. A., Crespo-Rivas, J. C., Hidalgo, Á., Gil-Serrano, A., Moreno, J., Rodríguez-Navarro, D. N., Buendía-Clavería, A., Ollero, J., Ruiz-Sainz, J. E., and Vinardell, J. M. 2012. Sinorhizobium fredii HH103 does not strictly require KPS and/or EPS to nodulate Glycyrrhiza uralensis, an indeterminate nodule-forming legume. Arch. Microbiol. 194:87-102.

Masson-Boivin, C., Giraud, E., Perret, X., and Batut, J. 2009. Establishing nitrogen-fixing symbiosis with legumes: How many rhizobium recipes? Trends Microbiol. 17:458-466.

Meyer, F., Goesmann, A., McHardy, A. C., Bartels, D., Bekel, T., Clausen, J., Kalinowski, J., Linke, B., Rupp, O., Giegerich, R., and Pühler, A. 2003. GenDB-An open source genome annotation system for prokaryote genomes. Nucleic Acids Res. 31:2187-2195.

Okazaki, S., Zehner, S., Hempel, J., Lang, K., and Göttfert, M. 2009. Genetic organization and functional analysis of the type III secretion system of Bradyrhizobium elkanii. FEMS (Fed. Eur. Microbiol. Soc.) Microbiol. Lett. 295:88-95.

Parada, M., Vinardell, J. M., Ollero, F. J., Hidalgo, A., Gutiérrez, R., Buendía-Clavería, A. M., Lei, W., Margaret, I., López-Baena, F. J., GilSerrano, A. M., Rodríguez-Carvajal, M. A., Moreno, J., and Ruiz-Sainz, J. E. 2006. Sinorhizobium fredii HH103 mutants affected in capsular polysaccharide (KPS) are impaired for nodulation with soybean and Cajanus cajan. Mol. Plant-Microbe Interact. 19:43-52.

Pellock, B. J., Teplitski, M., Boinay, R. P., Bauer, W. D., and Walker, G. C. 2002. A LuxR homolog controls production of symbiotically active extracellular polysaccharide II by Sinorhizobium meliloti. J. Bacteriol. 184:5067-5076.

Perret, X., Freiberg, C., Rosenthal, A., Broughton, W. J., and Fellay, R. 1999. High-resolution transcriptional analysis of the symbiotic plasmid of Rhizobium sp. NGR234. Mol. Microbiol. 32:415-425.

Pueppke, S. G., and Broughton, W. J. 1999. Rhizobium sp. strain NGR234 and $R$. fredii USDA257 share exceptionally broad, nested host ranges. Mol. Plant-Microbe Interact. 12:293-318.

Ribeiro, C. M., and Cardoso, E. J. B. N. 2012. Isolation, selection and characterization of root-associated growth promoting bacteria in Brazil Pine (Araucaria angustifolia). Microbiol. Res. 167:69-78.

Rice, P., Longden, I., and Bleasby, A. 2000. EMBOSS: The European molecular biology open software suite. Trends Genet. 16:276-277.

Ried, J. L., and Collmer, A. 1987. An nptI-sacB-sacR cartridge for constructing directed, unmarked mutations in gram-negative bacteria by marker exchange-eviction mutagenesis. Gene 57:239-246.

Rodrigues, J. A., López-Baena, F. J., Ollero, F. J., Vinardell, J. M., Espuny, M. R., Bellogín, R. A., Ruiz-Sainz, J. E., Thomas, J. R., Sumpton, D., Ault, J., and Thomas-Oates, J. 2007. NopM and NopD are rhizobial nodulation outer proteins: Identification using LC-MALDI and LC-ESI with a monolithic capillary column. J. Proteome Res. 6:1029-1037.

Rodríguez-Navarro, D. N., Rodríguez-Carvajal, M. A., Acosta-Jurado, S., Soto, M. J., Margaret, I., Crespo-Rivas, J. C., Sanjuan, J., Temprano, F., Gil-Serrano, A., Ruiz-Sainz, J. E., and Vinardell, J. M. 2014. Structure and biological roles of Sinorhizobium fredii $\mathrm{HH} 103$ exopolysaccharide. PLoS ONE 9:e115391.

Sambrook, J., Fritsch, E. F., and Maniatis, T. 1989. Molecular Cloning. A Laboratory Manual, 2nd Ed. Cold Spring Harbor Laboratory Press, Cold Spring Harbor, NY, U.S.A.

Sanchez-Contreras, M., Bauer, W. D., Gao, M., Robinson, J. B., and Downie, A. J. 2007. Quorum-sensing regulation in rhizobia and its role in symbiotic interactions with legumes. Philos. Trans. R. Soc. Lond. B Biol. Sci. 362:1149-1163.

Sanjuan, J., Carlson, R. W., Spaink, H. P., Bhat, U. R., Barbour, W. M., Glushka, J., and Stacey, G. 1992. A 2-O-methylfucose moiety is present in the lipo-oligosaccharide nodulation signal of Bradyrhizobium japonicum. Proc. Natl. Acad. Sci. U.S.A. 89:8789-8793.

Schmeisser, C., Liesegang, H., Krysciak, D., Bakkou, N., Le Quéré, A., Wollherr, A., Heinemeyer, I., Morgenstern, B., Pommerening-Röser, A., Flores, M., Palacios, R., Brenner, S., Gottschalk, G., Schmitz, R. A., Broughton, W. J., Perret, X., Strittmatter, A. W., and Streit, W. R. 2009. Rhizobium sp. strain NGR234 possesses a remarkable number of secretion systems. Appl. Environ. Microbiol. 75:4035-4045.

Schuldes, J., Rodriguez Orbegoso, M., Schmeisser, C., Krishnan, H. B., Daniel, R., and Streit, W. R. 2012. Complete genome sequence of the broad-host-range strain Sinorhizobium fredii USDA257. J. Bacteriol. 194:4483.

Schwientek, P., Szczepanowski, R., Rückert, C., Stoye, J., and Pühler, A. 2011. Sequencing of high $\mathrm{G}+\mathrm{C}$ microbial genomes using the ultrafast pyrosequencing technology. J. Biotechnol. 155:68-77.

Schwientek, P., Szczepanowski, R., Rückert, C., Kalinowski, J., Klein, A., Selber, K., Wehmeier, U. F., Stoye, J., and Pühler, A. 2012. The complete genome sequence of the acarbose producer Actinoplanes sp. SE50/110. BMC Genomics 13:112.

Simon, R. 1984. High frequency mobilization of gram-negative bacterial replicons by the in vitro constructed Tn5-Mob transposon. Mol. Gen. Genet. 196:413-420.

Simon, R., Priefer, U., and Pühler, A. 1983. Vector plasmids for in vivo and in vitro manipulations of gram-negative bacteria. Pages 98-106 in: Molecular Genetics of the Bacteria-Plant Interaction. A. Pühler, ed. Springer-Verlag, Berlin.

Simsek, S., Ojanen-Reuhs, T., Marie, C., and Reuhs, B. L. 2009. An apigenin-induced decrease in K-antigen production by Sinorhizobium $\mathrm{sp}$. NGR234 is y4gM- and nodD1-dependent. Carbohydr. Res. 344: 1947-1950.

Spaink, H. P., Aarts, A., Stacey, G., Bloemberg, G. V., Lugtenberg, B. J. J., and Kennedy, E. P. 1992. Detection and separation of Rhizobium and Bradyrhizobium Nod metabolites using thin-layer chromatography. Mol. Plant-Microbe Interact. 5:72-80.

Sugawara, M., Epstein, B., Badgley, B. D., Unno, T., Xu, L., Reese, J., Gyaneshwar, P., Denny, R., Mudge, J., Bharti, A. K., Farmer, A. D., May, G. D., Woodward, J. E., Médigue, C., Vallenet, D., Lajus, A., Rouy, Z., Martinez-Vaz, B., Tiffin, P., Young, N. D., and Sadowsky, M. J. 2013. Comparative genomics of the core and accessory genomes of 48 Sinorhizobium strains comprising five genospecies. Genome Biol. 14:R17.

Süss, C., Hempel, J., Zehner, S., Krause, A., Patschkowski, T., and Göttfert, M. 2006. Identification of genistein-inducible and type III-secreted proteins of Bradyrhizobium japonicum. J. Biotechnol. 126:69-77. 
Theunis, M., Kobayashi, H., Broughton, W. J., and Prinsen, E. 2004. Flavonoids, NodD1, NodD2, and nod-box NB15 modulate expression of the $y 4 w E F G$ locus that is required for indole-3-acetic acid synthesis in Rhizobium sp. strain NGR234. Mol. Plant-Microbe Interact. 17: 1153-1161.

Vinardell, J. M., Ollero, F. J., Krishnan, H. B., Espuny, M. R., Villalobo, E., Pueppke, S. G., and Ruiz-Sainz, J. E. 1997. ISRf1, a transposable insertion sequence from Sinorhizobium fredii. Gene 204:63-69.

Vinardell, J. M., López-Baena, F. J., Hidalgo, A., Ollero, F. J., Bellogín, R., Espuny, M. R., Temprano, F., Romero, F., Krishnan, H. B., Pueppke, S. G., and Ruiz-Sainz, J. E. 2004a. The effect of FITA mutations on the symbiotic properties of Sinorhizobium fredii varies in a chromosomalbackground-dependent manner. Arch. Microbiol. 181:144-154.

Vinardell, J. M., Ollero, F. J., Hidalgo, A., López-Baena, F. J., Medina, C., Ivanov-Vangelov, K., Parada, M., Madinabeitia, N., Espuny, M. R., Bellogín, R. A., Camacho, M., Rodríguez-Navarro, D. N., Soria-Díaz, M. E., Gil-Serrano, A. M., and Ruiz-Sainz, J. E. 2004b. NolR regulates diverse symbiotic signals of Sinorhizobium fredii HH103. Mol. PlantMicrobe Interact. 17:676-685.

Wassem, R., Kobayashi, H., Kambara, K., Le Quéré, A., Walker, G. C., Broughton, W. J., and Deakin, W. J. 2008. TtsI regulates symbiotic genes in Rhizobium species NGR234 by binding to tts boxes. Mol. Microbiol. 68:736-748

Weidner, S., Becker, A., Bonilla, I., Jaenicke, S., Lloret, J., Margaret, I., Pühler, A., Ruiz-Sainz, J. E., Schneiker-Bekel, S., Szczepanowski, R., Vinardell, J. M., Zehner, S., and Göttfert, M. 2012. Genome sequence of the soybean symbiont Sinorhizobium fredii HH103. J. Bacteriol. 194: 1617-1618.

Yu, N. Y., Wagner, J. R., Laird, M. R., Melli, G., Rey, S., Lo, R., Dao, P., Sahinalp, S. C., Ester, M., Foster, L. J., and Brinkman, F. S. 2010. PSORTb 3.0: Improved protein subcellular localization prediction with refined localization subcategories and predictive capabilities for all prokaryotes. Bioinformatics 26:1608-1615.

Zehner, S., Schober, G., Wenzel, M., Lang, K., and Göttfert, M. 2008. Expression of the Bradyrhizobium japonicum type III secretion system in legume nodules and analysis of the associated tts box promoter. Mol Plant-Microbe Interact. 21:1087-1093.

\section{AUTHOR-RECOMMENDED INTERNET RESOURCES}

Bielefeld BioInformatics Service's GeneFisher2 utility:

http://bibiserv.techfak.uni-bielefeld.de/genefisher2

Integrated Data Technologies website: http://eu.idtdna.com/site

Kyoto University Bioinformatics Center's GenomeNet database resources: http://www.genome.jp

National Center for Biotechnology Information (NCBI) Microbial Genomes Resources database:

https://www.ncbi.nlm.nih.gov/genomes/MICROBES/microbial_taxtree.html NCBI Sinorhizobium fredii database:

http://www.ncbi.nlm.nih.gov/genome/3067

WebACT database: http://www.webact.org 